\title{
MENORES TRANSEXUALES E INTERSEXUALES. LA DEFINICIÓN DE LA IDENTIDAD SEXUAL EN LA MINORÍA DE EDAD Y EL INTERÉS SUPERIOR DEL MENOR*
}

\author{
TRANSGENDER AND INTERSEX MINORS. THE DEFINITION OF SEXUAL \\ IDENTITY IN THE AGE MINORITY AND THE BEST INTERESTS OF THE \\ CHILD
}

\author{
Pilar Benavente MoredA**
}

\begin{abstract}
Resumen: El presente trabajo aborda la situación legal (en el ámbito estatal y autonómico) de los menores de edad transexuales e intersexuales. Para ello se parte de la vigente Ley 3/2007, de 15 de marzo, reguladora de la rectificación registral de la mención relativa al sexo de las personas, así como de las normas previstas en la Ley de Registro Civil y su Reglamento, que excluye la legitimación de los menores de edad para acceder al cambio de sexo, analizando igualmente la normativa que, ante la ausencia de respuesta estatal, han dado las Comunidades Autónomas que establecen criterios contradictorios a los aplicados a nivel nacional. Igualmente se analiza la evolución jurisprudencial sobre la materia, partiendo de la defensa del interés superior del menor, clave esencial de nuestro estudio, para tratar de fijar cuál ha de ser el camino a seguir en la definición de la propia identidad de los menores de edad.
\end{abstract}

Palabras clave: Transexualidad e intersexualidad, menores de edad, interés superior del menor, autonomía de la voluntad, cambio de sexo, cambio de nombre.

Abstract: This paper deals with the legal situation of transgender, transsexual and intersex minors (at the state and regional level). We begin our study with Law 3/2007, of 15 March, which regulates the modification of a person's sex, the registry, as well as of the norms laid down in

* http://doi.org/10.15366/rjuam2018.38.010

Fecha de recepción: 9 de noviembre de 2018.

Fecha de aceptación: 19 de diciembre de 2018.

** Profesora titular de Derecho Civil. Universidad Autónoma de Madrid.

Este trabajo se inserta como resultado del Proyecto CEAL-AL/2017-20, concedido por Resolución de 13 de junio de 2017, dentro de la $10^{\mathrm{a}}$ convocatoria de los Proyectos de Cooperación Interuniversitaria UAMSANTANDER con América Latina 2017/2017, cuya IP es Alma María Rodríguez Guitián, titulado: La libertad de autodeterminación en las relaciones familiares y sus límites como desafío del Derecho de Familia del siglo XXI en España y América Latina.

Igualmente constituye el desarrollo de diferentes conferencias impartidas en el ámbito del citado Proyecto de Investigación, fundamentalmente la impartida en el Congreso internacional: "Desafios actuales de la autonomía de la voluntad en las relaciones familiares y sus límites" celebrado en la Universidad Adolfo Ibañez (Chile), campus de Santiago y Viña del Mar los días 25, 26 y 27 de septiembre de 2018, con el título: "Menores transexuales e intersexuales. La definición de la identidad sexual en la minoría de edad y el interés superior del menor". 
the Civil Registry Law (LRC) and its Guidelines which excludes the legitimation of minors to change their sex. We also analyse the rules given by the autonomous communities in the absence of response from the state, which establish contradictory criteria to those applied at the national level. It also analyses the evolution of jurisprudence on the subject, starting from the defence of a minor's interests, a key element of our study, to try and determine what should be the way forward regarding the definition of the minors identity.

Keywords: Transgender and intersex minors, the best interests of the child, under age, sex change, autonomy of the will, name change.

SUMARIO: I. INTRODUCCIÓN; II. LAAUTONOMIA DE LA VOLUNTAD EN LAS RELACIONES VERTICALES: LAS FACULTADES DE LOS PROGENITORES Y DE LOS HIJOS MENORES PARA DEFINIR SU SEXUALIDAD/GÉNERO EN LOS LÍMITES DE LA PROGRESIVA CAPACIDAD DE OBRAR DE LOS MENORES. DERECHO ESTATAL Y DE LAS CCAA; 1 . Transexualidad e Intersexualidad y cambio de sexo. Breve referencia a la situación de los transexuales en España al amparo de la jurisprudencia tradicional y tras la Ley 3/2007 de 15 de marzo, reguladora de la rectificación registral de la mención relativa al sexo de las personas; 2 . Tratamiento a nivel estatal de los menores transexuales. Evolución jurisprudencial, de la admisión del cambio de nombre al futuro posible cambio de sexo: El Auto del TC de 10 de marzo de 2016. La Instrucción de la DGRN de 23 de octubre 2018 sobre cambio de nombre en el Registro Civil de las personas transexuales; A. Posición legal actual en cuanto al reconocimiento del derecho a la identidad sexual de los menores de edad; B. Evolución jurisprudencial. Del cambio de nombre al cambio de sexo en el Registro Civil. Ausencia de criterio jurisprudencial unitario; C. El camino hacia el reconocimiento: Del Auto del Tribunal Supremo de 10 de marzo de 2016 a la Instrucción de la DGRN de 23 de octubre de 2018 pasando por las diferentes Proposiciones de Ley de modificación de la Ley 3/2007;3. Normativa Autonómica sobre la materia a través de las diferentes Leyes de Identidad de género o reguladoras de los derechos de las personas LGTBI; A. Normativa autonómica sobre Identidad de Género y derechos de personas LGTBI; B. Derecho al reconocimiento de la Identidad sentida frente a la Identidad sexual registrada. ¿Conflicto de identidades administrativa vs registral? Inclusión y reconocimiento de los menores de edad; III. REFLEXIONES FINALES; IV. BIBLIOGRAFÍA.

\section{INTRODUCCIÓN}

Son numerosos los retos que se plantean actualmente en el ámbito de las relaciones paterno-filiales como consecuencia de la progresiva incorporación en las mismas de la autonomía de la voluntad, así como del reconocimiento generalizado de la autonomía progresiva del menor para tomar sus propias decisiones. Esta situación es común en la mayoría de los ordenamientos de nuestro entorno, incluido el español, sobre todo tras las reformas operadas en la Ley Orgánica de Protección Jurídica del Menor (LOPJM) de 1996 por la LO 8/2015, de 22 de julio (BOE 23.7.2015) y L 26/2015 de 28 de julio (BOE 29.7.2015) de modificación del sistema de protección a la infancia y a la adolescencia, poniéndose de 
relieve cada vez más como objeto de debate la posibilidad de actuación y toma de decisiones de los menores, en las denominadas edades limítrofes.

Por ello y de forma concreta, vinculado con aquellos casos en que los progenitores, que tienen el deber legal de proteger a los menores bajo su cuidado, pretenden ejercer el derecho a decidir frente al ya mencionado reconocimiento de la autonomía progresiva de los menores, nos centramos en un tema de relevante actualidad como es el de los menores transexuales e intersexuales, donde además del problema de si los mismos pueden equipararse a los adultos para poder solicitar el cambio de sexo y la rectificación registral del mismo, se plantean cuestiones igualmente relevantes, en los casos de intersexualidad, vinculadas con la conveniencia o adecuación de la realización de intervenciones tempranas para que quede determinado de manera definitiva el sexo del menor.

Hace unos años, en dos trabajos específicos ${ }^{1}$, abordamos de manera genérica el tema de los derechos de las personas transexuales e intersexuales pero sin centrarnos específicamente en la situación de los menores de edad, vinculándolo directamente con el derecho a la identidad sexual, la orientación sexual en las relaciones jurídico privadas y su protección en el ámbito de dichas relaciones, como manifestación del libre desarrollo de la personali$\mathrm{dad}^{2}$. Por ello muchas de las cuestiones que ahora analizaremos irán referidas inicialmente al contenido que sirvió de base a dichos trabajos.

Sin embargo ahora afrontamos el tema desde la perspectiva de los menores de edad y centrando el debate con un enfoque diferente, atendiendo al juego de la autonomía de la voluntad como manifestación, igualmente, del libre desarrollo de la personalidad y partiendo esencialmente de la evolución que, social, legal y jurisprudencialmente se ha ido produciendo en las últimas décadas sobre la materia.

En relación con lo indicado se abordará (al hilo de la vigente Ley 3/2007, de 15 de marzo, reguladora de la rectificación registral de la mención relativa al sexo de las personas ${ }^{3}$, en cuyo art. 1 se exige la mayoría de edad para solicitar la rectificación en el Registro Civil del sexo de las personas transexuales) la más reciente doctrina y jurisprudencia, así como las diferentes propuestas legislativas destinadas a permitir el cambio de sexo durante la minoría de edad y al hilo de la ya numerosa normativa autonómica reguladora de los derechos de las personas LGTBI y específicamente de los menores de edad.

No solo están siendo objeto de debate en los momentos actuales en el Parlamento sendas Proposiciones de Ley presentadas por el Partido Socialista y por Unidos Podemos,

1 BENAVENTE MOREDA P., «Orientación sexual e identidad de género y relaciones jurídico privadas», RGDC, núm. 17, 2013, pp.1-75; BENAVENTE MOREDA, P. «Identidad y contexto inmediato de la persona (identidad personal, el nombre de la persona, identidad sexual y su protección)», AFDUAM, núm. 17, 2013, pp. 105 a 144.

2 En este sentido, vid. ELVIRA PERALES, A., «Transexualidad y derechos», RGDC, núm. 17, 2013, pp. 3 y 7 , especialmente.

3 Boletín Oficial del Estado, 16 de marzo 2007, núm. 65, p.11251. 
en Comun Podem y en Marea (BOCG 3.3.2017 y 12.5.2017 respectivamente), destinadas entre otras cuestiones a modificar el citado art. 1 de la Ley de 3/2007, sino que el propio Tribunal Supremo (en adelante TS), en Auto de 10 de marzo de 2016 , ha planteado Cuestión de inconstitucionalidad contra la citada Ley $3 / 2007$, por excluir a los menores de edad de su ámbito de aplicación.

El tema no ha sido ajeno a la preocupación del legislador autonómico que en la mayoría de las Comunidades Autónomas (CCAA) ha abordado en los últimos años, dentro del ámbito de sus competencias, y dentro de las denominadas leyes de identidad de género o en defensa de los derechos de las personas LGTBI, su aplicación y reconocimiento en relación con los menores de edad, creando una situación compleja y de difícil encaje con la normativa estatal al permitir en algunos casos la incorporación del sexo o género «sentido» por parte de los menores en registros administrativos, académicos o sanitarios, al margen de los datos incorporados al Registro Civil como sistema de identificación único y común de todos los españoles.

Tampoco es ajeno el tema al resto de los ordenamientos jurídicos de nuestro entorno, tanto europeo como del resto del mundo (como es el caso de Argentina o Chile dentro de Latinoamérica o Irlanda o Malta, en Europa) donde se debate o se ha llegado a incorporar dentro de sus Leyes específicas de Identidad de Género a los menores, partiendo de esa capacidad progresiva mencionada anteriormente, que se visualiza claramente como una nueva vertiente de la entrada de la Autonomía de la Voluntad en campos del derecho hasta ahora impensables.

\section{LA AUTONOMIA DE LA VOLUNTAD EN LAS RELACIONES VERTICALES: LAS FACULTADES DE LOS PROGENITORES Y DE LOS HIJOS MENORES PARA DEFINIR SU SEXUALIDAD/GÉNERO EN LOS LÍMITES DE LA PROGRESIVA CAPACIDAD DE OBRAR DE LOS MENORES. DERECHO ESTATAL Y DE LAS CCAA}

\section{Transexualidad e intersexualidad y cambio de sexo. Breve referencia a la situación de los transexuales en España al amparo de la jurisprudencia tradicional y tras la Ley 3/2007 de 17 marzo reguladora de la rectificación registral de la mención relativa al sexo de las personas}

Aunque sea brevemente conviene que, con carácter previo y antes de adentrarnos en el análisis de la situación de los menores de edad transexuales o intersexuales, hagamos algunas reflexiones generales en relación con la situación legal en España de las personas trans e intersexuales, cuestión que ya habíamos abordado con anterioridad de una forma extensa, por lo que nos limitaremos en este punto a realizar un planteamiento general del

ATS 10.3.2016 (RJ/2016/1392); Id. Cendoj: 28079119912016200002. 
tema para evitar reiteraciones, así como a señalar las novedades que desde nuestras anteriores publicaciones se han producido en la materia.

En relación con el reconocimiento de derechos a las personas transexuales, y entre ellos especialmente al posible cambio de sexo, conviene recordar que el ordenamiento español ha pasado por diferentes fases, fruto de la evolución social y legal y consecuencia de la progresiva subsunción de los supuestos de transexualidad y su protección dentro del derecho al libre desarrollo de la personalidad.

En una primera fase, tan solo era posible la modificación registral del sexo de las personas en los supuestos de los llamados «estados intersexuales», considerados conforme a la interpretación que la jurisprudencia había venido realizando de los arts. 93.3 LRC de 1957 y 294 RRC de 1958 como de «discordancia originaria» entre el sexo inscrito y el real, lo que permitía la rectificación registral del sexo de la persona por vía del expediente gubernativo y con apoyo en la existencia de un error («indicación equivocada del sexo»), debiendo recurrirse en todo caso al procedimiento judicial correspondiente por tratarse de supuestos en que lejos de existir un error en la inscripción se produciría una contradicción con el sexo inscrito (art. 92 LRC).

En una segunda fase, en la jurisprudencia de nuestros tribunales comienza a admitirse, a partir de ciertas decisiones de la Dirección General de Registros y del Notariado (en adelante DGRN) y del TS, el cambio de sexo, tras la correspondiente cirugía de reasignación, a efectos registrales, pero sin considerar que tal modificación se producía a efectos cromosómicos, con la consiguiente falta de capacidad para el ejercicio de todos los derechos que derivarían del sexo reasignado, entre ellos, la imposibilidad de contraer matrimonio con personas del sexo contrario. Ello tan solo implicaba la posibilidad de modificación del nombre a efectos registrales lo que suponía a nuestro entender una clara y mayor discriminación de sus derechos individuales y sociales.

No obstante las decisiones en que se permitía el cambio de sexo se apoyaban básicamente en la necesidad de proteger «el derecho al libre desarrollo de la personalidad» (art.10 $\mathrm{CE}$ ), así como en la incipiente invocación, entonces, de los arts. 8 y 12 del Convenio de Roma, de Protección de los Derechos Humanos y Libertades Fundamentales ${ }^{5}$. Tal es la

5 La inclusión en el art. 8 del Convenio Europeo de Derechos Humanos, del derecho al cambio de sexo como medida de protección de la vida personal y privada de las personas transexuales ya ha sido objeto de reconocimiento expreso por el propio TEDH en numerosas sentencias, tal y como, dentro de las más recientes la de 6 de abril de 2017 (sec. 5. ${ }^{\text {a }}$ ) en el caso A.P., GARÇON AND NICOT v. FRANCE (TEDH/2017/49). Conforme a la misma el Tribunal considera que las autoridades francesas han vulnerado el derecho a la intimidad de los demandantes (de cambio de sexo), al exigir para ello la realización de una operación o tratamiento irreversible que puede conllevar la esterilización de los mismos. Para un análisis sobre la evolución de los derechos de las personas trans en la jurisprudencia del TEDH, vid. SANZ-CABALLERO, S, «El Tribunal Europeo de Derechos Humanos y su respuesta al reto de la transexualidad: Historia de un cambio de criterio», American University International law review, Tomo 29, núm. 4, 2013-2014, pp. 831-868. Igualmente ÁLVAREZ RODRÍGUEZ, I., «La organización de las Naciones Unidas y el derecho a la no discriminación por motivo de orientación sexual e identidad de género: apuntes para un debate», RGDC, 17, 2013 (Monográfico El movimiento LGTB 
posición mantenida por el TS en sentencia de 2 julio de 1987(RJ/1987/5045), en la que se hablaba de proteger "la ficción de hembra", permitiendo el cambio de nombre de hombre por el de mujer, en la de 18 de julio 1988(RJ/1988/5722), la de 3 de marzo 1989(RJ/1989/1993) o 19 abril 1991(RJ/1991/2725) y la DGRN en resoluciones como la de 2 octubre 1991(R. 8611), donde se admite la inscripción del cambio de sexo pero a efectos puramente sociales como remedio artificial en aras a defender el libre desarrollo de la personalidad, pero sin más consecuencias, por lo que no se permite que tal cambio le otorgue al transexual el derecho a contraer matrimonio.

Una tercera fase de la evolución en esta materia viene determinada por la admisión jurisprudencial del cambio de sexo no solo a efectos puramente sociales o meramente registrales, sino a todos los efectos, incluida la posibilidad de contraer matrimonio. Si bien manteniendo la exigencia de la previa operación de cirugía de reasignación y tratamiento hormonal.

Este cambio de criterio, anterior a la reforma operada en el CC por Ley 13/2005, que permite el matrimonio entre personas del mismo sexo, se introduce por la DGRN, utilizando curiosamente los mismos argumentos que antes habían servido para inadmitirlo (RDGRN 8 enero 2001(R. 2568); 31 enero 2001(R. 5095) y 25 enero 2005(R. 1954), permitiendo que aquellas personas que hubieran cambiado de sexo, e inscritos en el Registro Civil como tales, pudieran contraer matrimonio con otra persona del sexo diferente al suyo tras la modificación registral (con apoyo nuevamente en el art. $10 \mathrm{CE}$-libre desarrollo de la personalidad-y el propio art. $32 \mathrm{CE}$-derecho a contraer matrimonio).

El último escalón evolutivo en cuanto al tratamiento legal de la transexualidad en nuestro ordenamiento lo constituye fundamentalmente la Ley 3/2007 de 15 de marzo reguladora de la rectificación registral de la mención relativa al sexo de las personas, cuya trascendencia ${ }^{6}$ se encuentra, por un lado en el hecho de regular explícitamente en un texto legal la posibilidad registral del cambio de sexo y por otro lado, en la supresión en su art.

en perspectiva constitucional, ELVIRA PERALES, A., MATÍA PORTILLO, J., ARROYO GIL, A, coords.), pp. 1-34; DÍAZ LAFUENTE, J., «La protección de los derechos fundamentales frente a la discriminación por motivos de orientación sexual e identidad de género en el Unión Europea», RGDC, núm. 17, 2013, pp. 1-48; RUIZ-RUISUEÑO MONTOYA, F., «Los derechos de las personas LGTB en la Jurisprudencia del TEDH», $R G D C$, núm. 17, 2013, pp. 1-39. También reflexiona sobre la evolución del reconocimiento de los derechos de las personas trans ELVIRA PERALES, A., «Transexualidad y derechos», RGDC, núm. 17, 2013, pp. 5 y 6.

6 Efectivamente la Ley resulta relevante por los motivos expuestos, pero el legislador no aborda, como habría podido hacer, el tema de la transexualidad de una forma integral. No estamos ante una Ley integral sobre Identidad de Género, por lo que se dejan muchas cuestiones por resolver, entre ellas precisamente la ausencia de mención de los menores transexuales, o el reconocimiento de derechos en los diferentes ámbitos sociales, educativos, sanitarios etc..., lo que de alguna manera dio pie, como veremos, a que las CCAA comenzaran a legislar sobre el tema. Así lo señala ALVENTOSA DEL RIO, J., «Menores transexuales. Su protección jurídica en la Constitución y en la legislación española», REDC, núm. 107, 2016, p. $159<\mathrm{http}$ :/dx.doi.org/10.18042/ cepc/redc.10705>. A la ausencia del carácter integral de la Ley y sus consecuencias alude igualmente ELVIRA PERALES, A., «Transexualidad y derechos», ob. cit., p. 10. 
4.2 de la exigencia de cirugía de reasignación para permitir el acceso al Registro del cambio de sexo, siempre que se den las circunstancias previstas en dicho precepto:

a) Que se haya diagnosticado disforia de género, acreditada mediante informe de médico o psicólogo clínico, colegiados en España o cuyos títulos hayan sido reconocidos u homologados en España, y que deberá hacer referencia a la existencia de disonancia entre el sexo morfológico o género fisiológico inicialmente inscrito y la identidad de género sentida por el solicitante o sexo psicosocial, así como la estabilidad y persistencia de esta disonancia; a la ausencia de trastornos de personalidad que pudieran influir, de forma determinante, en la existencia de la disonancia reseñada en el punto anterior.

b) Que el transexual haya sido tratado médicamente durante al menos dos años para acomodar sus características físicas a las correspondientes al sexo reclamado. La acreditación del cumplimiento de este requisito se efectuará mediante informe del médico colegiado bajo cuya dirección se haya realizado el tratamiento o, en su defecto, mediante informe de un médico forense especializado. Sin embargo, no serán necesarios tales tratamientos médicos cuando concurran razones de salud o edad que imposibiliten su seguimiento y se aporte certificación médica de tal circunstancia?

La rectificación registral del sexo así realizada produce plenos efectos a favor de la persona (art. 5 Ley 3/2007), de tal forma que la resolución que acuerde la rectificación de la mención registral del sexo: a) tendrá efectos constitutivos a partir de su inscripción en el Registro Civil; b) permitirá a la persona ejercer todos los derechos inherentes a su nueva condición; c) el cambio de sexo y nombre acordado no alterará la titularidad de los derechos y obligaciones jurídicas que pudieran corresponder a la persona con anterioridad a la inscripción del cambio registral. Todo ello implica que a partir de tal momento será considerado del sexo modificado, pero que aquellos derechos y obligaciones jurídicas nacidas con anterioridad quedan inalteradas, lo que supone, por ejemplo, que en el caso de haber tenido hijos, como padre o madre seguirá siendo considerado como tal con las obligaciones y derechos inherentes a la patria potestad en relación con aquéllos.

Como consecuencia de la rectificación del sexo y nombre de la persona se procederá de oficio a rectificar todos los documentos relativos a la persona (art. 6). La expedición de tales documentos se hará a petición de parte, aunque quedan exentos del abono de las tasas correspondientes (D.A. 2.a), al no considerar tal expedición como supuesto imputable al interesado.

\footnotetext{
$7 \mathrm{Al}$ analizar los requisitos exigidos al respecto por la legislación alemana, Friedmann PFÄFFLIN considera que en general, tanto en la legislación alemana como en la de otros páises, la exigencia de requsitos diagnósticos, burocráticos y legales para lograr el reconocimiento del cambio de sexo son excesivos, por lo que considera que deberían suavizarse las exigencias. Vid. PFÄFFLIN, P., «Transgenderism and transsexuality medical and psichological viewpoints», en SCHERPE, J.M. (ed.), The legal status of transexual and transgender persons, Cambrigde (Intersentia), 2015, p. 23.
} 
En cuanto a la Intersexualidad ${ }^{8}$, a la que igualmente hicimos referencia expresa en los trabajos anteriormente mencionados, es considerada como una variación cromosómica que médicamente, conforme al modelo biomédico occidental ${ }^{9}$, es objeto de tratamiento para acomodar dicha variación cromosómica a la exigencia social que suprime la pluralidad intersexual y la reduce a una mínima expresión dual. La cirugía se encarga de la transformación de la anatomía de los genitales ambiguos. Con ello el modelo biomédico se ajusta al binario de sexo/género de las sociedades occidentales ignorando los ejemplos de sociedades no occidentales que discrepan de tal construcción social ${ }^{10}$.

En función de ello a los intersexuales (para quienes se ha dicho, el género se aprende como la lengua nativa) se les hace crecer como varones o hembras procediendo a temprana

8 Son números los estudios realizados sobre intersexualidad, de los que por su carácter didáctico y completo resaltaría en estos momentos obras como la de PLATERO MÉNDEZ, R., Transexualidades. Acompañamiento, factores de salud y recursos educativos, $2^{\mathrm{a}}$ ed., Barcelona (Bellaterra), 2014, pp.140-147. PLATERO pone de manifiesto la crudeza de la realidad que ha rodeado históricamente a la intersexualidad, al señalar que tradicionalmente, «esta curiosidad de la ciencia médica ... se traduce en protocolos de intervención temprana, donde los hospitales públicos y privados practican intervenciones sobre bebés que no pueden dar su consentimiento, al tiempo que a las familias a menudo se les recomienda guardar este secreto, incluso a sus propios hijos...» (pp.140-141). Por su parte Lorenzo BERNINI realiza un análisis en profundidad de la evolución del tratamiento de la Intersexualidad desde planteamientos críticos, manifestándose igualmente en contra de las operaciones tempranas de reasignación de sexo, que lejos de estar erradicadas siguen aplicándose. Vid. BERNINI, L. Las teorías Queer. Una introducción (trad. Albert Tola), Barcelona-Madrid (Egales), 2018, p.74 y ss. Obligada es la referencia, como referente absoluto sobre el tratamiento interdisciplinar e internacional de la Intersexualidad de la obra editada por SCHARPE, [SCHERPE, JM., DUTTA, A., HELMS, T., (eds.), The legal status of Intersex persons, Cambrigde (Intersentia), 2018, sobre cuyo contenido haremos puntualmente referencia a lo largo del presente trabajo.

9 En el estudio presentado por Ieauan HUGHES (NIHR Cambrigde Biomedical Research Center) sobre el desarrollo fetal del sexo de las personas, el autor, tras analizar las posibles causas de intersexualidad así como los momentos de desarrollo de la intersexualidad en recién nacidos o en la pubertad, concluye que la biología del desarrollo sexual en el feto describe un proceso binario caracterizado por el bipotencial del tejido embrionario para desarrollar órganos reproductivos masculinos o femeninos. El control de la vía dimórfica sexual definitiva está mediado por genes y hormonas clave que funcionan de manera dependiente del tiempo y la concentración durante una ventana crítica de la programación fetal. El conocimiento de esta vía proporciona un enfoque lógico para clasificar las causas de intersexualidad. Por ello solo los profesionales de la salud que trabajan en centros especializados debe realizar este trabajo y brindar apoyo a las personas con intersexualidad y sus familias. El mal uso de la terminología en el campo de la intersexualidad no es útil; se necesita claridad para centrarse en lo que son principalmente factores biomédicos frente a aquellos que son más relevantes desde una perspectiva social. Vid. HUGHES, I. «Biology of fetal sex development», en SCHERPE J.M., DUTTA, A. and HELMS T. (eds.), The legal Status of intersex persons, Cambridge (Intersentia), 2018, pp.25-44. Vid., igualmente, el estudio realizado por LAUROBA LACASA, E., «Las personas intersexuales y el derecho: Posibles respuestas jurídicas para un colectivo invisible», Derecho Privado y Constitución, núm 32, 2018, pp.16-19.

10 Resulta muy interesante y esclarecedor el análisis que al respecto realiza PLATERO MÉNDEZ cuando al estudiar la transexualidad y la diferente terminología utilizada al respecto, se refiere a «las personas que no cumplen o no conforman los mandatos de género (gender non-conforming)», refiriéndose a los niños que son más femeninos que otros, las niñas que son más masculinas que el resto, no encajan necesiariamente ni en la masculinidad ni la feminidad típicos. Es una infancia, apunta, cuya expresión de identidad es persistente e intensa, que rompe con la asignación que se hizo en su nacimiento. Vid. PLATERO MÉNDEZ, R., Transexualidades. Acompañamiento, factores de salud y recursos educativos, ob. cit., pp. 42 a 46. 
edad a la asignación de su identidad, privándoseles del conocimiento de su auténtica identidad (posición mantenida hasta la década de los noventa) ${ }^{11}$.

Dicho esto, ya en su momento partíamos de una serie de interrogantes sobre los que la doctrina especializada ya se venía pronunciando y que merecen ser tomados en consideración ${ }^{12}$ :

a) Primero, si debía replantearse el mantenimiento de la dualidad/binomio sexual (hombre/ mujer), tal y como hasta ahora se mantiene, descartando el planteamiento médico tradicional de definir desde el momento mismo del nacimiento el sexo (masculino o femenino) de las personas ${ }^{13}$. Queda claro que tal exigencia definitoria de la dualidad se pone de manifiesto en ordenamientos como el español, donde junto con la inscripción del nacimiento ha de constar igualmente su sexo. La pregunta es si sigue siendo necesario elegir o podemos romper social, cultural y legalmente con el binarismo ${ }^{14}$.

Como ya señalábamos en otra ocasión, cada vez son más las voces discrepantes al mantenimiento del modelo biomédico ajustado al binario sexo/género, así como a los procedimientos médicos y protocolos para reconducir la sexualidad a tal binomio, poniendo de manifiesto que el sistema biomédico tradicional aumenta más que aliviar las dificultades de nacer intersexual. Se trata de impedir, en definitiva, las operaciones quirúrgicas en la infancia y dejar que la persona tome la decisión en la edad adulta, como manifestación del libre desarrollo de su personalidad, lo que conduciría obviamente a desestructurar el binario sexo/género ${ }^{15}$.

11 NIETO PIÑEROBA, J.A. Transexualidad, intersexualidad y dualidad de género, Barcelona (Bellaterra), 2008, pp. 47 y ss.; LAUROBA LACASA, E., «Las personas intersexuales y el derecho: Posibles respuestas jurídicas para un colectivo invisible», ob. cit., pp.23-26.

12 BENAVENTE MOREDA, P., «Orientación sexual e identidad de género y relaciones jurídico privadas», Revista General de Derecho Constitucional, núm. 17, 2013, pp. 17 y ss., especialmente p. $22<\mathrm{https}$ ://www. iustel.com/v2/revistas/detalle_revista.asp?id=3\&numero=17>.

13 Autores como Marina CAMPS, siguiendo a Maracuello y Elósegui, considera sin embargo que en los supuestos de intersexualidad no se produce un problema de identidad sexual, porque cada sujeto tiene un sexo asumido, varón o mujer, que para él no ofrece duda; no hay un problema psicológico, apunta, y no tiene en absoluto la percepción de pertenecer a un tercer sexo. Vid. CAMPS MERLO, M., Identidad sexual y Derecho. Estudio Interdisciplinario del transexualismo, Navarra (Eunsa), 2007, pp. 105.

14 BENAVENTE MOREDA, P., «Orientación sexual e identidad de género y relaciones jurídico privadas», ob. cit. pp.18-21.

15 Relevante resulta al respecto la obra de ANNE FAUSTO STERLING, Profesora de biología y estudios de género en el departamento de Biología Molecular y Celular y Bioquímica de la Universidad de Brown. La autora se manifestó abiertamente en contra de la dualidad de sexos en sus numerosas publicaciones, destacando al respeto su ensayo The Five Sexes publicado en 1993 en la prestigiosa revista Sciences, revisado posteriormente en 2000; y Cuerpos sexuados: La política de género y la construcción de la sexualidad (2000), traducido al español en 2006 (Barcelona. Melusina). Igualmente, desde un punto de vista antropológico analiza el tema NIETO PIÑEROBA, J.A., «Transexualidad, Intersexualidad y dualidad de género», ob. cit. Afirma por su parte LÓPEZ MORATALLA, refiriéndose a las personas con condición intersexual, el origen genético de tal condición, derivado de un trastorno del desarrollo gonadal -«ovotesticular»-, que presentan ambigüedad en las estructuras gonadales y en los genitales. Se trata, apunta, de una malformación que no conlleva efectos 
El activismo en este punto se ha visto desarrollado y arropado en los diferentes Foros Internacionales Intersex celebrados a los largo de los últimos años. Destacando al respecto el III Foro celebrado en Malta en diciembre de 2013, que origina la Declaración de Malta ${ }^{16}$, así como el IV Foro celebrado en Ámsterdam en abril de 2017. Igualmente

cerebrales, ni transexualismo. Los investigadores recomiendan en tales casos no tener prisa en asignarles desde el nacimiento un sexo, de forma arbitraria. La asignación de sexo, afirma la autora, se ha hecho, generalmente con demasiada precipitación en muchos casos, eliminando estructuras gonadales y/o genitales, y potenciando otras mediante intervenciones quirúrgicas y tratamientos hormonales. Los conocimientos actuales sin embargo pueden permitir conducirles hacia una mejor armonía con las características corporales. LÓPEZ MORATALLA, N, «La identidad sexual: personas transexuales y con trastornos del desarrollo gonadal "no existen sexos, solo roles": un experimento antropológico necesitado de la biotecnología», Cuadernos de Bioética, núm. 78, vol. XXIII, 2012, pp. 348 y 367 y ss. Disponible en <http://www.aebioetica.org/revistas/2012/23/78/341.pdf>. Una de las activistas de tal posicionamiento es la norteamericana Cheryl Chase, fundadora en EEUU de la «Intersex Society of North America». Cheryl, nació como hermafrodita auténtica, de forma que sus gónadas tenían elementos de tejido tanto ovárico como testicular. Ella fue sometida a los 18 meses a una operación de extracción de clítoris. Durante toda la infancia y madurez se evidencia que en ningún momento se tuvo en cuenta la situación real por la que Cheryl estaba pasando, ni existió apoyo alguno a su condición indefinida, motivo por el que fundó el ISNA, habiéndose convertido en una ferviente defensora de introducir modificaciones en los tratamientos médicos en relación con estos casos. Vid. YRONWODE, A., «Las personas intersexuales cuestionan las operaciones realizadas en la infancia», Archivo y Biblioteca de Lesbianas, Mujeres Bisexuales y Diferentes (Traducción: Alejandra Sardá), Synapse, Universidad de California, EE.UU, abril $1999<$ www. isna.org/node/64>. Ciertamente los supuestos de intersexualidad son minoritarios (se ha apuntado que 1 de cada 20000 nacimientos), pero se aboga por la modificación de los tratamientos médicos, por erradicar las intervenciones quirúrgicas en la infancia y respetar la decisión del intersexual en su etapa adulta, postura apoyada por algunos profesionales del sector médico y del derecho (NIETO PIÑEROBA, J.A, «Transexualidad, Intersexualidad y Dualidad de Género», ob. cit., p. 48). Da cuenta LÓPEZ MORATALLA de algunos supuestos de Trastornos ovotesticulares (estados intersexuales), como la Estrofia Cloacal (defecto de toda la pelvis y su contenido, que se produce durante la gestación de un feto XY, varón, y que conlleva una grave insuficiencia fálica. La causa de la malformación es una alteración de las enzimas 5-reductasa y 17-hidroxi-esteroide. De recién nacidos parecen niñas con un gran clítoris). La autora alude a un estudio realizado sobre 16 jóvenes, genéticamente varones, que padecían EC, a lo largo del periodo entre sus 5 hasta sus 16 años. A 14 de ellos se les había sometido a asignación neonatal al sexo femenino; los padres de los dos restantes se negaron a hacerlo. Mediante cuestionarios ampliamente detallados se evaluó el desarrollo de la función sexual y la identidad. Ocho de los 14 sujetos asignados al sexo femenino se declararon varones durante el curso de este estudio, y los 2 educados como varones mantuvieron su identidad masculina. Los 16 tenían entre moderados y marcados intereses y actitudes masculinas, con independencia de la crianza como niñas o niños. A la luz de tales estudios, apunta LÓPEZ MORATALLA, las intervenciones clínicas en estos niños deben ser reexaminadas. El hecho de que los pacientes con EC posean testículos histológicamente normales, aunque sin descender en el período neonatal, implica que se han desarrollado en un medio hormonal prenatal típicamente masculino. Así pues, estos niños, que nacen genética y hormonalmente como varones, se identifican desde la infancia como varones, a pesar de ser criados como mujeres, y someterse a una cirugía feminizante tras el nacimiento. Vid. LÓPEZ MORATALLA, N, «La identidad sexual: personas transexuales y con trastornos del desarrollo gonadal "no existen sexos, solo roles": un experimento antropológico necesitado de la biotecnología», ob. cit., p. 368. Vid., igualmente, la posición crítica sobre el binarismo de Lorenzo BERNINI, quien analizando la evolución en cuanto al reconocimiento de las personas trans en Italia, considera que el binarismo sexual no es una ley inmutable de la naturaleza, sino un dispositivo histórico de poder, cuyas normas pueden ser contestadas, reformadas o incluso abolidas. Vid. BERNINI, L., Las teorías Queer. Una introducción, ob. cit. p.74.

16 Vid. Web Europe Organisation International Europe (https://oiieurope.org/malta-declaration/) [Consultado el 07/11/2018]. 
relevantes son la Declaración de Darlington ${ }^{17}$ y la Declaración de Viena ${ }^{18}$, ambas de marzo de 2017, en las que se sigue reclamando el fin de las esterilizaciones sin consentimiento, así como la posibilidad de garantizar que cualquier persona intersex pueda dar su consentimiento informado a cualquier intervención quirúrgica, reivindicando así mismo la necesaria despatologización de la diversidad de las características sexuales en los protocolos y clasificaciones internacionales. Igualmente se propuso ya en 2013 que el sexo no se configurara como una categoría dentro de los documentos oficiales ${ }^{19}$.

Cuando en 2013 analizábamos con cierto detalle el devenir de los acontecimientos en relación con el tratamiento de la intersexualidad (a cuyo contenido me remito en estos momentos), ya apuntábamos cómo en algunos ordenamientos como el alemán, lo que podría considerarse como planteamiento de «ciencia ficción» se estaba abriendo paso tras la reforma operada en la Legislación sobre el estado civil de las personas, que regula las inscripciones en el Registro Civil [Personenstandsgesetzt (PSTG, PersStdG)] de 3 de noviembre de 1937(RGB1. I S. 1146) en su redacción de 19 de febrero de 2007 (BGB1. I S. 122), por Ley de 7 de mayo de 2013 (Gesetz zur Änderung personenstandsrechtlicher Vorschriften) (BGB1. I S. 1122) de 14 de mayo), en vigor desde el 1 de Noviembre del 2013. Su nuevo art. 22 señalaba, fruto de tal reforma, que si no se le puede atribuir un sexo al niño recién nacido, entonces no habrá que introducir dato alguno relativo al sexo en el Registro de Nacimientos («Kann das Kind weder dem weiblichen noch dem männlichen Geschlecht zugeordnet werden, so ist der Personenstandsfall ohne eine solche Angabe in das Geburtenregister einzutragen»). La Ley que modifica la legislación sobre el Estado civil, abordaba precisamente como algo absolutamente novedoso en Europa, la posibilidad de omitir la referencia al sexo (masculino o femenino), permitiendo que en los certificados de nacimiento no se registre el sexo de los recién nacidos.

17 En la Declaración de Darlington se establece específicamente es sus aparatados 7 y 8 las siguientes declaraciones que se reproducen básicamente en todas las declaraciones anteriores y posteriores:

«...Human rights and legal reform. 7. We call for the immediate prohibition as a criminal act of deferrable medical interventions, including surgical and hormonal interventions, that alter the sex characteristics of infants and children without personal consent. We call for freely-given and fully informed consent by individuals, with individuals and families having mandatory independent access to funded counselling and peer support. 8. Regarding sex/gender classifications, sex and gender binaries are upheld by structural violence. Additionally, attempts to classify intersex people as a third sex/gender do not respect our diversity or right to self determination. These can inflict wide-ranging harm regardless of whether an intersex person identifies with binary legal sex assigned at birth or not...». Disponible en $<$ https://intersexday.org/wp-content/uploads/2017/03/Darlington-Statement.pdf) $>$

18 Vid. https://oiieurope.org/statement-1st-european-intersex-community-event-vienna-30st-31stmarch-2017/ [Consultado el 07/11/2018].

19 Vid. los documentos completos en la web de ILGA. Disponible en $<$ https://www.ilga $<$ https://www. ilga.org/4th-international-intersex-forum-media-statement $>$ y $<$ https://www.ilga-europe.org/what-we-do/ our-advocacy-work/trans-and-intersex/intersex/events/3rd-international-intersex-forum $>$ [consultado el 07/11/2018]. Igualmente pueden consultarse en SCHERPE JM, DUTTA and HELMS T. (eds), The legal Status of intersex persons, 2018, pp. 7-22. Vid. también en este sentido las observaciones realizadas por PLATERO MÉNDEZ, R., Transexualidades. Acompañamiento, factores de salud y recursos educativos, ob. cit., pp. 145146. 
En este punto Alemania ha dado un paso más, que viene de la mano de su Tribunal Constitucional, que en Sentencia de 10 de octubre de $2017^{20}$ fue más allá en la valoración del denominado «tercer sexo», al considerar insuficiente la posibilidad de no dejar registro del sexo (masculino o femenino) en el Registro Civil, exigiendo al poder legislativo la necesaria reforma para permitir la inscripción «en positivo» y con carácter de permanencia, de una tercera vía de inscripción que no necesariamente haya de corresponderse con el género femenino o masculino, posibilitando en definitiva la inscripción del nacido como «intersexual»o «diverso $»^{21}$.

Precisamente el Tribunal Constitucional alemán se apoya en el derecho constitucionalmente reconocido a la protección de la personalidad, por lo que las personas que no son ni hombres ni mujeres tienen derecho a inscribir su identidad de género de forma «positiva» en el registro de nacimiento. El mandato que el TC Alemán confería en su sentencia al poder legislativo le obligaba a acompasar la legislación de Registro Civil con la normativa constitucional antes de finalizar el año 2018. En respuesta a dicho mandato, el Consejo de Ministros alemán aprobó el 15 de agosto de 2018 un Proyecto de Ley para introducir legalmente la posibilidad de la inscripción del tercer sexo, bajo la nomenclatura de género «iverso $»^{22}$.

20 BVerfG, Order of the First Senate of 10 October 2017 - 1 BvR 2019/16 - paras. (1-69). <http://www. bverfg.de/e/rs20171010_1bvr201916en.html>. Vid., igualmente, No. 95/2017 of 08 November 2017. <https:// www.bundesverfassungsgericht.de/SharedDocs/Pressemitteilungen/EN/2017/bvg17-095.html >. En relación con la Ley Alemana de 2013 resultan interesantes las observaciones realizadas por Tobías HELMS, en relación con las consecuencias legales del nuevo sistema de inscripción registral en el que no figuraba la inscripción de sexo masculino o femenino cara a la celebración de un posible matrimonio por dichas personas (ha de tenerse en cuenta que en Alemania es legal el matrimonio igualitario desde octubre de 2017) o cara a la determinación de la filiación de los hijos que pudieran tener las personas intersexuales. Vid. HELMS, T., «The 2013 german law: Analysis and criticism» en SCHERPE J.M., DUTTA, A., and HELMS T. (eds.), The legal Status of intersex persons, 2018, pp. 369-381.

${ }_{21}$ Yendo más allá de la propia legislación alemana que acabamos de reflejar, en Mendoza (Argentina) con apoyo en el art. 2 de la Ley de Identidad de Género de mayo de 2012 la Dirección del Registro Civil ha permitido que en la partida de nacimiento de una persona no conste sexo alguno («Definición. Se entiende por identidad de género a la vivencia interna e individual del género tal como cada persona la siente, la cual puede corresponder o no con el sexo asignado al momento del nacimiento, incluyendo la vivencia personal del cuerpo. Esto puede involucrar la modificación de la apariencia o la función corporal a través de medios farmacológicos, quirúrgicos o de otra índole, siempre que ello sea libremente escogido. También incluye otras expresiones de género, como la vestimenta, el modo de hablar y los modales». <http://www.boletinoficial.gov.ar/Inicio/Index. castle>. «La Dirección del Registro Civil de Mendoza dispuso a través de la resolución 420/2018 "proceder a la solicitud de esta persona que requirió el reconocimiento legal de su identidad de género autopercibida". Por eso se llevó a cabo la correspondiente rectificación registral, ya que fue solicitado en forma expresa que en su partida de nacimiento y DNI no se consigne sexo alguno, de acuerdo a Ley 26.743 de Identidad de Género...». $<$ https://www.lanacion.com.ar/2187971-mendoza-registro-civil-mendocino-avalo-pedido-no $>$ [consultado el 02/11/2018].

$22<$ https://www.dw.com/es/intersexualidad-alemania-aprueba-el-tercer-g\%C3\%A9nero/a-45097647> [Consultado el 15/10/2018]. La ruptura con el binarismo en la inscripción registral no solo se está planteando en Alemania, sino también en otros países como Australia, Nepal o Paquistán. Vid., al respecto, PLATERO MENÉNDEZ, R., Transexualidades. Acompañamiento, factores de salud y recursos educativos, ob. cit., pp. 46 
b) La segunda cuestión, que no necesariamente excluye el planteamiento del primer interrogante realizado, era plantearnos «cuándo y quién» debe decidir, en su caso, sobre una hipotética definición del sexo, de la identidad sexual de la persona. Lo que nos conduce a determinar si, de admitir la respuesta positiva al primer interrogante planteado, cabe pensar que tal decisión debería ser asumida, madurada y valorada por quien se encuentra en la situación de definir su propia identidad sexual, esto es, el propio intersexual cuando adquiera efectivamente tal capacidad de decisión.

La cuestión, ya abordada, como se ha indicado, en otra publicación nuestra, adquiere si cabe mayor relevancia en los momentos actuales, donde, frente a las dudas que planteábamos entonces, quizás incipientemente dentro de la doctrina sobre la materia, ahora se revela más acuciante resolver sobre el particular debido a algunos factores que conviene tener presentes:

Por un lado, y de manera preferente, conviene tener en cuenta la relevancia que en esta materia ha adquirido la nueva valoración y definición del interés superior del menor, que se ha puesto de manifiesto con las reformas operadas en diferentes textos legales, básicamente en la LOPJM, por la LO 8/2015 de 22 de julio y Ley 26/2015, de 28 de julio, ambas de protección a la infancia y a la adolescencia. La inclusión de un nuevo art. 2 en la LOPJM, en el que de manera extensa se trata de definir el alcance y contenido del «interés superior del menor», que hasta ahora se definía exclusivamente fruto de la interpretación jurisprudencial y doctrinal. Ello marca de manera evidente los límites y características que han de guiar al intérprete y aplicador del derecho cuando se trata de tomar en consideración precisamente lo que haya de definirse como interés superior del menor.

En la línea indicada, baste señalar que, conforme al art. 2.2.d) LOPJM, a los

«efectos de la interpretación y aplicación en cada caso del interés superior del menor, se tendrán en cuenta los siguientes criterios generales, sin perjuicio de los establecidos en la legislación específica aplicable, así como de aquellos otros que puedan estimarse adecuados atendiendo a las circunstancias concretas del

\footnotetext{
y ss. En el caso de la legislación del Sur de Australia cabe ese tipo de inscripción de un «tercer sexo» conforme a la Legislación de nacimientos, fallecimientos y matrimonios, de 2011. En el caso australiano el tema es complejo en todo caso, dada la diferencia regulatoria atendiendo al especial sistema legal de carácter federal que establece un sistema competencial por materias conforme a la Constitución. Así en materia de inscripción de los nacimientos en todas las jurisdicciones, salvo en la Ley del Sur de Australia, el sexo del nacido ha de ser registrado y su determinación se basa en la inspección física de sus genitales. En Sur Australia sin embargo el sexo del niño solo debe ser registrado si se determina. Sin embargo, no está claro si dicho registro debe ser masculino o femenino, o si se permiten legalmente otras categorías. Cabe el registro como varón, como mujer, intersexual, indeterminado y «para ser informado». En todo caso la ausencia de concreción en la inscripción tiene un límite temporal de seis meses, para reducir la presión sobre los padres en la toma de decisión sobre la definición del sexo de su hijo. Vid. FENTON-GLYNN, C., «The legal status of intersex persons in Australia», en SCHERPE J.M., DUTTA, A. and HELMS T. (eds.), The legal Status of intersex persons, Cambridge (Intersentia), 2018, pp. 243-253.
} 
supuesto: ... d) La preservación de la identidad, cultura, religión, convicciones, orientación e identidad sexual o idioma del menor, así como la no discriminación del mismo por éstas o cualesquiera otras condiciones, incluida la discapacidad, garantizando el desarrollo armónico de su personalidad...».

Los criterios señalados, sigue indicando el precepto, se ponderarán teniendo en cuenta, entre otros elementos generales:

«...a) La edad y madurez del menor; b) La necesidad de garantizar su igualdad y no discriminación por su especial vulnerabilidad, ya sea por la carencia de entorno familiar, sufrir maltrato, su discapacidad, su orientación e identidad sexual, su condición de refugiado, solicitante de asilo o protección subsidiaria, su pertenencia a una minoría étnica, o cualquier otra característica o circunstancia relevante. c) El irreversible efecto del transcurso del tiempo en su desarrollo. d) La necesidad de estabilidad de las soluciones que se adopten para promover la efectiva integración y desarrollo del menor en la sociedad, así como de minimizar los riesgos que cualquier cambio de situación material o emocional pueda ocasionar en su personalidad y desarrollo futuro. e) La preparación del tránsito a la edad adulta e independiente, de acuerdo con sus capacidades y circunstancias personales».

\section{Tratamiento a nivel estatal de los menores transexuales. Evolución jurisprudencial, de la admisión del cambio de nombre al futuro posible cambio de sexo: El Auto del TS de 10 de marzo de 2016. La Instrucción de la DGRN de 23 de octubre 2018 sobre cambio de nombre en el Registro Civil de las personas transexuales}

A. Posición legal actual en cuanto al reconocimiento del derecho a la identidad sexual de los menores de edad ${ }^{23}$

Centrándome ya en el objeto esencial de este estudio, daré un paso más, partiendo del derecho de toda persona a su propia identidad personal digna de protección no solo en el ámbito constitucional (ex art.10 CE) sino también en el ámbito del Convenio Europeo de Derechos Humanos (ex art.8 CEDH), para valorar si los menores de edad, al ser dignos de la misma protección, deberían estar legitimados para cambiar de sexo durante la minoría de edad.

\footnotetext{
23 Sobre el particular vid. MALDONADO, J., «El reconocimiento del derecho a la identidad sexual de los menores transexuales en los ámbitos registral, educativo y sanitario», RJUAM, núm. 36, 2017-II, pp.135-169; RAVETLLAT BALLESTÉ, I., «El derecho a la identidad (de género) de la infancia y la adolescencia: del paradigma de la patología a la autodeterminación», La Leydigital, LA LEY 11968/2017, pp.1-31.
} 
De la mano de tal debate se añade además si procede dar un paso más haciendo inexigible para proceder al cambio de sexo su consideración como patología acompañada por tanto de la exigencia de tratamientos médicos, psicológicos y endocrinos previos a la modificación de la inscripción registral del sexo de las personas o, como ocurre en otras legislaciones europeas y latinoamericanas ${ }^{24}$, podrá definirse la identidad de, incluso los menores de edad, con la mera manifestación de voluntad instando el cambio de sexo por no corresponderse con la identidad sentida. Pero ello constituye elemento común en el debate sobre la transexualidad, afecte a personas mayores o menores de edad ${ }^{25}$.

Como ocurriera otrora, parecen reproducirse, en cuanto a la evolución de los derechos de los menores transexuales, los mismos esquemas que han guiado la evolución en el ordenamiento español sobre el reconocimiento del cambio de sexo con carácter general, hasta llegar a la vigente regulación. De la mano, como suele ocurrir, de la reivindicación social ${ }^{26}$

\footnotetext{
24 Aunque sería interesante realizar, como lo haremos en otro momento, un estudio comparativo con la legislación en otros ordenamientos de nuestro entorno, no es nuestro objetivo en este momento, por lo que puede servir de referencia al objeto indicado la referencia a dos ordenamientos que en este punto pueden considerarse como pioneros. Es el caso de la Ley 26.743, de Identidad de Género de Argentina, de 9 de mayo de 2012 (publicada el 24 de mayo) <http://www.boletinoficial.gov.ar/Inicio/Index.castle $><$ https:// www.boletinoficial.gob.ar/\#! DetalleNorma/70107/20120524>. Conforme a la citada Ley no se requiere (ex art. 4) ninguna certificación ni tratamiento médico previo para proceder al cambio de sexo, tan solo la mera manifestación de voluntad del solicitante. En relación con el procedimiento en el caso de Argentina, vid. GIOSA, LM., SCHIRO, M.V., DUNNE, P., "The legal status of transexual and transgender persons in Argentina» en SCHERPE, J.M. (ed.), The legal status of transsexual and trangender persons, Cambridge (Intersentia), 2015, pp. 571-584. En sentido parecido se manifiesta la Ley de Identidad de Género de Malta (Gender identity, gender expression and sex characteristics act, of 14th April, 2015- ACT XI of 2015, as amended by Act XX of 2015. $<\mathrm{http} / /$ www.justiceservices.gov.mt/DownloadDocument.aspx?app=lom\&itemid=12312\&l=1>. Conforme a la citada legislación no es necesario tratamiento hormonal ni cirugía de reasignación para solicitar el cambio de sexo, para lo cual será suficiente con la presentación de la correspondiente solicitud de reasignación sexual ante en encargado del Registro, que deberá resolverse en 15 días, lo que lleva aparejado no solo el cambio de sexo: de nombre sino también del resto de los datos del solicitante.

25 Téngase en cuenta que si bien la OMS (CIE-10, epgrf F64) venía considerando la transexualidad como una enfermedad entre los transtornos de la personalidad. Sin embargo en la actualidad, tras la publicación del CIE-11 en 18 de julio de 2018 (HA60), la transexualidad abandona el capítulo de los «trastornos» pasando al relativo al de «las condiciones relativas a la salud sexual», denominándola como incongruencia de género, entre el experimentado por el individuo y el género que se le asigna al nacer. Consultado en $<\mathrm{http} / / \mathrm{www}$.who. int/classifications/icd/en/> y <https://icd.who.int/browse11/1-m/en\#/http://id.who.int/icd/entity/90875286>.

26 Existen, no solo a nivel nacional, sino también internacional, diferentes organizaciones y asociaciones de transexuales o destinadas a la protección de los derechos de los menores transexuales. Tal es el caso de CHRYSALLIS, asociación creada a nivel estatal el 1 de julio de 2013. Como se indica en la propia presentación de la Asociación, entre sus miembros y fundadores existía un nexo fundamental:

«...: todas teníamos una hija o hijo transexual (las identidades no binarias tardaron un poco más en aparecer) y necesitábamos respuestas que no encontrábamos. Ni la legislación existente ni las administraciones, contemplaban nuestra realidad, la respuesta que recibíamos por parte de les profesionales no nos satisfacía (en numerosísimas ocasiones, su desconocimiento era la causa del sufrimiento de nuestr@s niñ@s) y no existían colectivos similares que estuvieran trabajando en ello. No estábamos dispuestas a que vivieran una infancia y juventud sin que su identidad sexual fuera reconocida y nació Chrysallis». Disponible en $<$ https://chrysallis.org.es $>$
} 
y de la solución puntual del caso particular y concreto parece que nos dirigimos hacia un posible reconocimiento y aplicación de la normativa general señalada a los menores de edad. Obviamente, la cuestión, en su caso, deberá matizarse (como por otro lado lo hacen las legislaciones de nuestro entorno que reconocen los derechos de los menores transexuales y la posibilidad de los mismos de proceder al cambio de sexo durante la minoría de edad) para determinar si se atiende en ello a la progresiva madurez del menor, si se requiere la representación de los progenitores o representantes legales o/y si en su caso es imprescindible la autorización judicial ${ }^{27}$. Incluso creemos que en el debate debería tenerse en cuenta la necesaria distinción entre sexo y género, porque no parece que los discursos sobre el tema (a nivel estatal y autonómico por ejemplo) sean siempre coincidentes ${ }^{28}$.

También dentro del ámbito nacional adquiere relevancia la Fundación Daniela <http://www.fundaciondaniela. org/>, constituida como organización sin ánimo de lucro destinada a terminar con la discriminación que sufren los niños y niñas y adolescentes transexuales y transgénero. A nivel internacional existen diferentes asociaciones destinadas igualmente a la protección de los intereses de los menores transexuales, tal es el caso de Canadá (http://enfantstransgenres.ca/); Alemania $<$ https://www.trans-kinder-netz.de/was-bieten-wir-an.html $>$; Irlanda $<$ http://www.teni.ie/> o Chile <https://www.transitar.cl/> o la Fundación Iguales <https://www.iguales.cl/>, entre otras.

27 No es ajeno al debate, y por tanto es algo que no puede obviarse, el planteamiento que desde muchos sectores se realiza ante las posibles dudas acerca de la futura irreversibilidad de los deseos del menor durante la edad adulta, tal y como lo plantean autores como DE MONTALVO JÄÄSKELAINEN, que analiza con profundidad el tema de la capacidad del menor transexual y las facultades de sus padres a la hora de adoptar decisiones acerca de los tratamientos médicos que han de permitirle optar por el sexo sentido y para ello se centra, de nuevo, en el análisis del art. 9 de la Ley de Autonomía del Paciente de 2002, reformada recientemente por la Ley 26/2015. Vid. DE MONTALVO JÄÄSKELAINEN, F., «Problemas legales acerca del tratamiento médico de la disforia de género en menores de edad transexuales», RGDC, núm. 24, 2017, pp. 23 y ss., en concreto, p. 27. Vid., igualmente, en relación con el tema de las intervenciones médicas, PLATERO MÉNDEZ que analiza con profundidad los tratamientos con bloqueadores hormonales durante la minoría de edad, como remedio, apunta, para quienes presenten malestar evidente. Igualmente debe pensarse en la repercusión que tales tratamientos pueden tener sobre la fertilidad futura de los jóvenes, especialmente sobre las mujeres trans. Vid. PLATERO MÉNDEZ, R., Transexualidades. Acompañamiento, factores de salud y recursos educativos, ob. cit., pp.66-67. Analiza igualmente con detalle LÓPEZ GÚZMAN los pros y los contras de las intervenciones médicas tempranas, no tanto desde el punto de vista de quiénes hayan de consentirlas, sino atendiendo a la conveniencia de las mismas para el desarrollo personal y emocional de los menores de edad. Para el autor, en los últimos años se ha producido un alarmante aumento de intervenciones en edades muy tempranas (3/4 años) que pueden acarrear consecuencias negativas en el desarrollo, aún incompleto, de la identidad del menor. Interesante resultan por otro lado las valoraciones realizadas por LÓPEZ GUZMÁN, ante lo que considera una cierta contradicción de ciertos sectores en el tratamiento de la situación de los menores de edad trans frente a los menores intersexuales, ya que se evidencia que hay grupos proclives al cambio de sexo de los menores transexuales, mostrando sin embargo reticencias a las intervenciones tempranas en menores intersexuales. Ha de decirse, opinamos nosotros, que si bien ciertamente pueden darse tales contradicciones, quizás no existan como tal si el problema se analiza desde el punto de vista de la existencia del consentimiento o no del menor afectado, atendiendo al criterio reiterado, de valorar la progresiva madurez del menor. Vid. LÓPEZ GUZMAN, J., Transexualismo y salud integral de la persona. Valencia (Tirant lo Blanch), 2016, pp.137-146.

28 La tendencia hoy en día a hablar del género fluido, como realidad vital, nos inclina a poder pensar en prescindir (frente el binomio obligado del sexo masculino o femenino, que provoca irreparablemente el cambio de sexo cuando el sentimiento no se corresponda con el asignado al nacer) de la necesidad de tener 
Por otro lado conviene tener presente, que ante la ausencia de una Ley Integral de Género, han sido las Comunidades Autónomas inicialmente las que, al legislar sobre el derecho a la Identidad de Género y reconocimiento de los derechos de las personas LGTBI en el ámbito (sea inicialmente) de sus respectivas competencias, han comenzado a decantar la situación en una vertiente imparable a la par que, desde mi punto de vista, bastante descoordinada, regulando por un lado los derechos de las personas trasn, incluidos los menores de edad y permitiendo, por otro (no en todas las CCAA como veremos), la posibilidad de que los menores transexuales se identifiquen conforme al género sentido sin necesidad, en algunos casos, de ningún tipo de diagnóstico previo ni tratamiento médico, hormonal o psicológico de tipo alguno. Lo que nos aproxima no tanto al reconocimiento de la transexualidad como tal, sino a una valoración más allá de calificaciones sexuales específicas, ubicada más en el derecho de cada individuo a definirse conforme al género sentido o con el que cada cual se identifica, al margen del sexo biológico al que se pertenezca.

Obviamente no es competencia de las Comunidades Autónomas definir la identidad registral de las personas, cuestión de competencia estatal, tal y como se desprende del art. 149.1. $8^{\circ} \mathrm{CE}$, por lo que en modo alguno la legislación autonómica podría haber interferido en la forma de identificación registral de las personas, objeto específico de una normativa estatal como es la Ley de Registro Civil. Por ello como veremos, en los textos (o algunos de ellos) aprobados en el ámbito autonómico, se fija la posibilidad de que las personas transexuales -incluidos los menores de edad-puedan llegar a identificarse «administrativamente» y dentro del ámbito competencial autonómico correspondiente, conforme al género sentido al margen de la identificación en el Registro Civil conforme a los criterios marcados por la Ley estatal, creando, desde nuestro punto de vista, un doble sistema de identificación que puede resultar cuanto menos problemático.

Igualmente como ya se señaló más arriba, conviene tener presente, como veremos, el posicionamiento del TS que mediante Auto de 10 de marzo de $2016(\mathrm{RJ} / 2016 / 1392)$ ha planteado Cuestión de inconstitucionalidad de la Ley 3/2007 que venimos citando, centrada específicamente en la posible inconstitucionalidad de sus arts. 1 y 4 , al no permitir la citada Ley el acceso al cambio de sexo más que a las personas mayores de edad.

que reconducir la situación y sentimiento personal a una necesaria y obligatoria transformación física que en el fondo implica seguir manteniendo el encorsetamiento del binarismo. En este sentido resulta absolutamente recomendable la lectura de la colección de artículos recopilados por Fiona JOY GREEN y May FRIEDMAN como editoras del libro Buscando el final del Arcoiris: una exploración de las prácticas de crianza desde la fluidez de género, [Traducido por Yolanda Fontal y revisado por Raquel (Lucas) Platero)], Barcelona (Bellaterra), 2015. Dentro del citado libro resulta de obligada referencia el artículo de WARD, J., «iAparta tu género binario de mi infancia!: hacia un movimiento a favor de la autodeterminación de género en la infancia» (pp. 59-68), en el que se aboga precisamente por romper con el encorsetamiento del binarismo durante la infancia. 


\section{¿Cuál es el ámbito legal en el que nos movemos en los momentos actuales?}

Pues la realidad, a efectos de rectificación legal del sexo de un menor de edad no es otra que, conforme al art. 1 de la Ley 3/2007 tan solo se legitima a las personas de nacionalidad española, mayores de edad y con capacidad suficiente para ello, para solicitar la rectificación registral de la mención del sexo. Ello, obviamente, si bien cierra el paso para que los menores de edad, sea personalmente o a través de sus representantes legales, puedan acceder a tal rectificación, no impide no obstante, como no lo hace la legislación de autonomía del paciente ${ }^{29}$, que los menores, a partir de los 16 años, sigan en su caso el tratamiento hormonal, médico y psicológico exigido por la propia Ley $3 / 2007$, ex art. 4 para llegar a poder culminar de forma completa el tránsito hacia el sexo demandado al alcanzar la mayoría de edad ${ }^{30}$.

Ello no obsta a que se venga demandando desde hace tiempo la posibilidad de acceder al cambio registral durante la minoría de edad, lo que ha dado lugar al debate sobre la necesidad de acometer una reforma en la normativa estatal e incluso a que el propio TS haya planteado, como ya hemos indicado, Cuestión de inconstitucionalidad sobre la Ley 3/2007, al no admitirlo.

Todo ello encuentra su apoyo fundamental en la necesidad de dar protección a los menores de edad transexuales, avalada por la necesaria actuación de los poderes públicos atendiendo por encima de todo al interés superior del menor que ya se ha puesto de manifiesto sobradamente no solo en el ámbito europeo sino también y además en la propia LOPJM 1996 tras la reforma operada en la misma por la LO 8/2015 y la Ley 26/2015 de protección a la infancia y la adolescencia.

Así se constata en la Resolución de la Asamblea Parlamentaria del Consejo de Europa núm. 2048(2015) sobre Discriminación contra personas transgénero en Europa ${ }^{31}$. Además, siguiendo los criterios claramente delimitados en el ámbito europeo, el legislador español,

29 Vid. art. 9 Ley de Autonomía del Paciente (RCL/2002/2650) tras las modificaciones introducidas por la

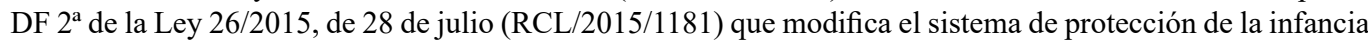
y la adolescencia, en relación con el art.9 de la LOPJM (LO 1/1996, de 15 enero, RCL 1996/145).

DE MONTALVO JÄÄSKELÄINEN, tras analizar la modificación sufrida por el art. 9 citado plantea sus dudas en relación con los tratamientos hormonales en la medida en que puedan considerarse, por sus efectos, incluidos en el ámbito del art. 9,4 como actuaciones de grave riesgo para la vida o salud del menor, por lo que el menor no podría autorizarlos, aún siendo mayor de 16 años. Se refiere el autor a los tratamientos hormonales de segunda fase, por los riesgos asociados (esterilidad, entre otros y su posible carácter irreversible). Va más allá al considerar que en tales supuestos tampoco serviría suplir el consentimiento con la intervención de los padres, centrando precisamente en la irreversibilidad o no de los deseos del menor. Vid. DE MONTALVO JÄÄSKELÄINEN, F., «Problemas legales acerca del tratamiento médico de la disforia de género en menores de edad transexuales», ob. cit., pp. 27 y ss.

30 Vid. FERRER RIBA, J., y LAMARCA MARQUÉS, A., «The legal status of transgender and transexual persons in Spain», en SCHERPE, J.M. (ed.), The legal Status of Transsexual and Transgender persons, Cambridge (Intersentia), 2015, pp.268 y 269.

31 Assembly debate on 22 April 2015 (15th Sitting) (see Doc. 13742, report of the Committee on Equality and Non-Discrimination, rapporteur: Ms Deborah Schembri). Text adopted by the Assembly on 22 April 2015 
al reformar la LOPJM de 1996 por Ley 26/2015, de 28 de julio, de protección a la infancia y a la adolescencia, introduce precisamente como principios rectores de la actuación de los poderes públicos en relación con los menores (ex art.11.2.1), entre otros: «... El libre desarrollo de su personalidad conforme a su orientación e identidad sexual».

Es por ello que, tanto antes, como sobre todo después de que el TS planteara la Cuestión de inconstitucionalidad sobre la Ley $3 / 2007$, precisamente invocando la posible inconstitucionalidad de su art. 1 al no legitimar a los menores de edad para rectificar en el Registro su sexo, son numerosas las Propuestas legislativas presentadas en este sentido en las que nos centraremos posteriormente.

No obstante en este momento resulta interesante referirse a la Resolución de la Comisión de Asuntos Institucionales del Parlamento Catalán (presentada a propuesta de Juns pel Si) de 6.7.2016 (BOPC 13.7.2016), de modificación de la Ley 3/2007 para permitir el acceso de los menores a la rectificación registral de su sexo, que fue aprobada por unanimidad con la abstención del Partido Popular ${ }^{32}$.

Existe igualmente una Proposición no de Ley (162/000165) presentada por el Grupo Parlamentario Ciudadanos, sobre la inscripción en el Registro Civil de nombres de personas cuya identidad sexual no coincide con su mención registral relativa al sexo (BOCG 8.4.2016) en la que precisamente se instaba a emitir una Instrucción en el sentido de permitir la inscripción en el Registro Civil del nombre con el que se sienta identificada la persona transexual, menor o mayor de edad, sin tener en cuenta la identidad sexual asignada en el

(15th Sitting) (Discrimination against transgender people in Europe) en la que la Asamblea llama a los Estados miembros, en materia de reconocimiento legal de género a:

«...6.2.1. develop quick, transparent and accessible procedures, based on self-determination, for changing the name and registered sex of transgender people on birth certificates, identity cards, passports, educational certificates and other similar documents; make these procedures available for all people who seek to use them, irrespective of age, medical status, financial situation or police record; 6.2.2. abolish sterilisation and other compulsory medical treatment, as well as a mental health diagnosis, as a necessary legal requirement to recognise a person's gender identity in laws regulating the procedure for changing a name and registered gender (...) 6.2.4. consider including a third gender option in identity documents for those who seek it; 6.2 .5 . ensure that the best interests of the child are a primary consideration in all decisions concerning children...».

Disponible en: $\mathrm{http} / /$ assembly.coe.int/nw/xml/XRef/Xref-DocDetails-EN.asp?fileid=21736\&lang=EN\&search=cmVzb2x1dGlvbiAyMDQ4ICgyMDE1KXxjb3JwdXNfbmFtZV9lbjoiT2ZmaWNpYWwgZG9jdW1lbn RzInxwdWJsaXNoZGF0ZTpbTk9XL0RBWS01WUVBU1MgVE8gK10=http//assembly.coe.int

32 La citada Resolución encuentra su origen en la Propuesta de la Comisión de Asuntos Institucionales del Parlamento Catalán (presentada a propuesta de Juns pel Si) de 6.7.2016 (BOPC 13.7.2016), de modificación de la Ley 3/2007 para permitir el acceso de los menores a la rectificación registral de su sexo que fue aprobada por unanimidad con la abstención del Partido Popular. (BOPC, 128,72). Como señalamos, la propuesta fue aprobada como Resolución 207/XI del Parlament de Catalunya, sobre el canvi de nom i la rectificació de la menció registral del sexe dels menors i els migrants transsexuals en el Registre Civil. Disponible en: $<$ https:// www.parlament.cat/document/bopc/172975.pdf\#page=8> 
momento del nacimiento ${ }^{33}$. Proposición que constituye claramente el antecedente inmediato de la Instrucción de la DGRN de 23 de octubre de 2018 que venimos citando.

Igualmente en los últimos años (2017 y 2018) se han presentado diferentes Proposiciones de Ley con la finalidad, precisamente, de permitir que los menores de edad tengan acceso, entre otras cuestiones abordadas, a la posible rectificación registral de su sexo en el Registro Civil. A ellas nos referiremos posteriormente, si bien centrándonos en aquellas que se encuentran actualmente activas en el Parlamento.

\section{B. Evolución jurisprudencial. Del cambio de nombre al cambio de sexo en el Registro Civil. Ausencia de criterio jurisprudencial unitario}

El primer paso destinado a permitir la rectificación en el Registro del cambio de sexo de los menores de edad ha venido, casuísticamente, de la mano del intento de modificación registral del nombre de los menores transexuales con la finalidad de adecuarlo a su identidad y género sentidos, dado que tal y como hemos visto más arriba no cabe el cambio de sexo hasta la mayoría de edad ${ }^{34}$. Ello sin embargo planteaba y plantea problemas, dada la regulación aún vigente prevista en la LRC de 1957 y su Reglamento de 1958. Problemático resultaría igualmente el cambio de nombre sin cambio de sexo conforme a lo previsto en la aún no vigente a tales efectos LRC 2011.

Antes de adentrarnos en la solución ofrecida en la práctica por los encargados del Registro Civil y, en su caso, por la DGRN conviene que veamos técnicamente la vía legalmente prevista para poder acceder al cambio de nombre en el Registro Civil y los problemas que ha planteado en la práctica tratar de aplicar dicha normativa en los casos de menores transexuales cuya identidad sexual no coincide con la sentida por el propio menor.

Como ya hemos señalado, la solicitud del cambio de nombre en el Registro ha sido inicialmente la elegida (diríamos que como mal menor) por los progenitores de los menores de edad transexuales, que se identifican y sienten como personas del sexo contrario a aquél que les ha sido asignado al nacer, y que por tanto han venido recurriendo a la pretensión de rectificar el nombre en el Registro acorde al correspondiente a la identidad sentida.

¿Cuáles son las exigencias previstas para la determinación y en su caso modificación del nombre en la LRC? Trataremos de analizar la respuesta tanto de la aún vigente LRC de 1957, de la que previsiblemente estará en vigor en este tema a partir de junio de 2020,

33 BOCG. Serie D. núm. 49, 8.4.2016, pp.11 a 14.

34 Tal exigencia del cambio de nombre ha venido justificada en muchas ocasiones por el hecho de que ya durante la minoría de edad se haya comenzado el tratamiento hormonal, durante el cual, el menor es identificado y se identifica con un nombre que ya no se corresponde con su identidad de género realmente sentida, por lo que se ha venido reivindicando al menos el derecho a acceder temporalmente o provisionalmente a documentación conforme al citado género sentido. En tal sentido, vid. FERRER RIBA, J., y LAMARCA MARQUÉS, A., «The legal status of transgender and transexual persons in Spain», ob. cit., p. 269. 
la LRC de 2011 y del RRC de 1958 (a salvo que antes de la completa entrada en vigor de la Ley se redacte un nuevo Reglamento acorde con los postulados de la misma, lo que por otro lado sería deseable).

La respuesta que la LRC 1957 y RRC 1958 dan específicamente al tema viene de la mano de los arts. $54^{35}, 59$ y 60 de la LRC y 209 y 210 RRC.

Conforme a dichos preceptos, no se puede poner un nombre a una persona que haga confusa su identificación o induzca a error en cuanto al sexo. Por otro lado, el cambio de nombre requiere justa causa y habitualidad de aquél cuyo cambio se pretende.

En el caso del cambio de nombre de los menores de edad transexuales se dan (o pueden darse) sin duda los requisitos señalados anteriormente (habitualidad en el uso del nombre y justa causa) para proceder legalmente a dicha modificación si el menor es conocido y usa con habitualidad el nombre cuyo cambio pretende, al mismo tiempo que no cabe duda de la existencia de justa causa para proceder a dicho cambio cuando el menor se siente identificado como una persona del sexo contrario al que le corresponda biológicamente por nacimiento y siente y vive conforme al género sentido.

Sin embargo existen igualmente argumentos (nuevamente con el texto legal en la mano), para defender la posición contraria puesto que el menor sigue teniendo asignado un sexo (que no puede cambiar mientras siga siendo menor de edad) que normalmente no se corresponderá con el nombre que pretende le sea asignado registralmente, tal y como señala expresamente el art. 54.2 LRC citado, salvo, como veremos, en los casos en los que se trate de un nombre ambiguo asignable tanto al sexo masculino como femenino ${ }^{36}$.

Precisamente esta dicotomía (se cumplen unos requisitos pero no otros) es la que se ha venido produciendo en las decisiones adoptadas para dar ese primer paso o no darlo y por tanto, permitir o no el cambio de nombre en el Registro Civil de un menor transexual. Existen numerosos Autos de diferentes Registros Civiles en lo que se ha permitido el cambio de nombre, bajo el apoyo de la «justa causa y la habitualidad» en el uso del nombre modificado. Al mismo tiempo la DGRN, frente a lo dicho anteriormente, no ha avalado los cambios de nombre que claramente evidencien una contradicción entre el sexo del menor y el nombre solicitado, admitiendo exclusivamente aquellos nombres que tengan una cierta ambigüedad que permita, digamos, una doble identificación (masculina o femenina).

En cuanto se refiere a la regulación en la LRC de 2011 la cuestión aparece regulada expresamente en sus arts. 51.2 y 52 . Conforme al primero de los preceptos citados y variando un poco en cuanto al contenido del art. 54 LRC de 1957, se establece que «no podrán

\footnotetext{
${ }_{35}$ El art. 54, en su apartado 2 debe su redacción a la DF. $2 .^{\text {a }}$, tres, de la Ley 3/2007 de 15 de marzo, reguladora de la rectificación registral de la mención relativa al sexo de las personas.

36 Como ya hemos visto más arriba, el partido de Ciudadanos en el Congreso presentó una Proposición no de Ley (162/000165) sobre inscripción en el Registro Civil de los nombres de personas cuya identidad sexual no coincide con su mención registral relativa al sexo (BOCG 8.4.2016. Serie D. General, núm. 49, pp. 11 a 14).
} 
imponerse nombres que sean contrarios a la dignidad de la persona ni los que hagan confusa la identificación», completando el segundo, en relación con el cambio de nombre que «El Encargado del Registro Civil, mediante procedimiento registral, podrá autorizar el cambio de nombre previa declaración del interesado, que deberá probar el uso habitual del nuevo nombre, y siempre que concurran las demás circunstancias exigidas en la legislación del Registro Civil».

A la vista del nuevo/futuro contenido de la LRC, podría pensarse que resulta más flexible la posición de los preceptos mencionados ya que al no vincular el nombre con el sexo de la persona, sino con la identidad/identificación de la misma, puede pensarse que da juego a la posibilidad de descartar el sexo como elemento definitorio de la designación del nombre y vincular este, como se hace, con la dignidad de la persona y con la ausencia de confusión en la identificación, que no necesariamente tiene que venir de la mano del sexo asignado al nacer sino con la idea de identidad sentida por quien pretende la modificación de su nombre. Pese a lo indicado y tras la mención que ya hicimos y haremos posteriormente a la Instrucción de la DGRN de 23 de octubre de 2018, auguramos desde estas páginas un nuevo (¿el último?) cambio en la ya maleada y maltratada LRC de 2011 para acomodarla de nuevo a los criterios fijados nuevamente de la mano de la DGRN y no del legislador.

Obviamente, este doble rasero a la hora de resolver no crea sino una situación de inseguridad jurídica que específicamente ha tratado de paliar la mencionada Instrucción de la DGRN de 23 de octubre de 2018.

Pues bien, con los mimbres legales indicados y ya descendiendo al terreno práctico, existen por un lado numerosos supuestos en los que los encargados del Registro Civil han comenzado a admitir el cambio de nombre de los menores (masculino/femenino conforme a la identidad de género sentida ${ }^{37}$. Incluso en algún supuesto se ha permitido no solo el

37 El Auto del RC de Córdoba, de 17.1.2013 (Expt. 1905/2012), en expediente de solicitud de cambio de nombre promovido por los progenitores de un menor de edad, resuelve, de acuerdo con los arts. 54 LRC y 219 RRC, aceptando el cambio de nombre de una menor, llamada Sofía, por el nombre de David, sin entrar en el debate sobre la posible conflicto al incurrir en "error en cuanto al sexo" que indica el propio art.54 LRC 1957 a lo que igualmente aluden los arts. 51 y 52 LRC 2011 (preceptos que aún no se encuentran en vigor), al aludir a la no imposición de nombres que hagan confusa la identificación de la persona. En el mismo sentido, el Auto del RC de Vitoria-Gasteiz, de 26.9.2013 (Expt. 1465/2013) en que igualmente se insta el cambio de nombre, en este caso el mismo nombre por su acepción femenina (Nahier por Nahiane), apoyándose básicamente en el art. 209.4 RRC que permite al juez encargado del Registro Civil, previo expediente, el cambio de nombre por el utilizado habitualmente esgrimiendo que el menor se identifica frente a terceros con el nombre propuesto como consecuencia «del reconocimiento de su verdadera identidad sexual, lo que acredita la justa causa legalmente establecida y dicho cambio y en ningún caso perjudica a terceros...». Igualmente el Auto del RC de Málaga de 16 de septiembre de 2013 (núm. expt. 2376/2013) autoriza el cambio de nombre claramente masculino por otro femenino, promovido igualmente a instancia de los progenitores del menor de 16 años (emancipado previamente por los padres), aplicando los arts. 59.4 y 209.4 RRC que permiten el cambio de nombre por el utilizado habitualmente (arts. 60 LRC y 210 RRC), señalándose específicamente en este caso que procedía el cambio pese a tratarse de un menor bilógicamente varón y ello pudiera inducir a error en cuanto al sexo (FD $2^{\circ} .^{\circ}$. Se señalan estos supuestos como ejemplo, pero tal y como menciona la DGRN en su Instrucción de 23 de 
cambio de nombre sino también el sexo del menor, como es el caso de sendos Autos de los Registros Civiles de Mislata y Valencia de marzo de 2016 en los que se permitió el acceso al Registro del cambio de sexo y de nombre de dos menores transexuales acordes con su identidad de género realmente sentida entendiendo que también los menores, al tenor del art. 1 de la Ley 3/2007 debían entenderse legitimados a través de sus representantes legales ${ }^{38}$.

Por otro, la doctrina emanada de la DGRN en las resoluciones que se han venido pronunciando sobre el tema ha venido rechazando los cambios de nombre que claramente sean contrarios al sexo legalmente establecido, partiendo de que

«aunque las prohibiciones del art. 54, II LRC han de interpretarse restrictivamente en su aplicación al caso concreto, con mayor razón cuando una determinación demasiado rigurosa del alcance de la norma puede afectar a los derechos al libre desarrollo de la personalidad, a la intimidad personal y a la propia imagen constitucionalmente reconocidos (cfr. arts. 10.1 y 18.1 de la Constitución) y, por ello, la doctrina de la Dirección General circunscribe la prohibición a los nombres que designan inequívocamente a personas de sexo distinto al de la afectada por el cambio ...» [(RDGRN 1.4.2016 (JUR $2017 \backslash 280907)]$.

En el mismo sentido resuelve la RDGRN de 2.12.2016 (JUR/2018/158012) que específicamente reitera lo señalado en la resolución anterior, matizando no obstante que el Centro Directivo ha venido admitiendo el cambio de nombre en caso de los menores transexuales que, cumpliendo con los requisitos exigidos por el art. 4 de la Ley 3/2004, al no poder cambiar de sexo hasta la mayoría de edad, optasen por «nombres neutros» que no den lugar a la discordancia señalada en el art. 54 LRC de 1957 en relación con el sexo que legalmente les corresponde.

Tampoco había venido prosperando, siguiendo la lógica de las resoluciones anteriormente citadas la solicitud en aquellos casos en los que se instaba el cambio del sexo y del nombre del menor transexual en el Registro, por ausencia de legitimación activa de conformidad con las exigencias del art. 1 de la Ley 3/2007, al requerirse para ello la mayoría de edad del solicitante y carecer los progenitores de poder de representación del menor para

octubre de 2018, se encuentran referenciados más de cien supuestos en los que se ha admitido con los mismos argumentos señalados anteriormente el cambio de nombre por los encargados del Registro Civil.

38 Así se interpretó que, «de acuerdo con la Constitución, aunque "es verdad que esa Ley no contempla expresamente la posibilidad de que una persona menor de edad pueda instar la rectificación registral de la mención relativa al sexo, la mención que hace al 'mayor de edad y con capacidad suficiente para ello' no debe ser interpretada como una implícita exclusión de los menores e incapaces de la posibilidad de solicitar tal rectificación, pues no se podría entender semejante trato discriminatorio que hiciera a estas personas de peor condición legal, cerrándoles la vía legal más ágil, sencilla y económica para la solución de su problema. Muy al contrario, ese silencio legal debe ser interpretado en el sentido de que, no pudiendo tales personas actuar por si a causa de su minoría de edad o de su incapacidad, lo podrán hacer si actúan representados por sus padres o tutores, que complementen su capacidad de obrar"». Disponible en $<$ https:/gaceta.es/noticias/ juezas-permiten-primera-vezmenores-cambiar-sexo-dni-04042016-2019>. 
instar tal rectificación, al tratarse de un acto personalísimo. Tal es la posición mantenida en

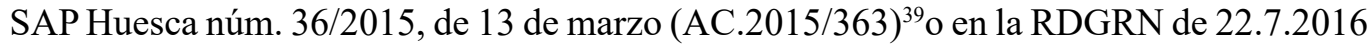
(JUR/2018/77459).

C. El camino hacia el reconocimiento: Del Auto del Tribunal Supremo de 10 de marzo de 2016 a la Instrucción de la DGRN de 23 de octubre de 2018 pasando por las diferentes Proposiciones de Ley de modificación de la Ley 3/2007

Tras describir la situación legal y jurisprudencial por la que ha atravesado los últimos años la situación de los menores de edad transexuales abordamos en este punto los hitos especialmente relevantes en relación con la materia que auguran un futuro en el que se permita la modificación registral del sexo de los menores de edad y que vienen de la mano, por un lado del TS y de la DGRN y por otro, de diversas Proposiciones de Ley presentadas en el Congreso que apuntan en la dirección indicada. La clave está, desde nuestro punto de vista, en que fruto de todos los elementos señalados se pueda llegar a una normativa coherente, trasversal y protectora que tome en consideración todas las implicaciones directas e indirectas que conlleva el reconocimiento de los derechos de los menores de edad transexuales (lo que implicará de manera adicional, una revisión de la normativa autonómica sobre la materia).

1. Mediante Auto del Pleno de la Sala $1^{\mathrm{a}}$ del TS de 10 de marzo de 2016 (RJ/2016/1392) se plantea Cuestión de inconstitucionalidad contra la Ley 3/2007 por presunta vulneración de los arts. 15, 18.1 y 43.1 CE, en relación al art. 10.1 CE y en relación fundamentalmente con el art. 1 de aquélla, que limita a las personas mayores de edad la legitimación para solicitar en juicio declarativo ordinario la rectificación de la mención registral del sexo y del nombre en casos de personar transexuales con disforia de género ${ }^{40}$.

El origen del presente Auto se encuentra en la solicitud paterna de rectificación registral en la inscripción de nacimiento de la hija menor de edad, en octubre de 2014. En este caso la menor había sido diagnosticada (endocrino, psiquiátrica y psicológicamente) con trastorno de identidad de género, con remisión al endocrino para iniciar el tratamiento hormonal. Tras la negativa del Registrador a inscribir el cambio de sexo y de nombre y abierto el proceso ordinario ante los tribunales, tanto en Instancia [SJPI de Huesca de 5.1.2015 (JUR/2015/239585)] como en Apelación [SAP de Huesca de 13.3.2015

\footnotetext{
39 Sentencia que precisamente constituye el antecedente del Auto del TS de 10 de marzo de 2016 en el que se plantea Cuestión de inconstitucionalidad de la Ley 3/2007.

40 Al hilo precisamente del citado Auto del TS, SANCHEZ FREYRE reflexiona sobre el diferente tratamiento de doctrina y jurisprudencia en relación con el ejercicio de los derechos fundamentales por parte de los menores de edad. Vid. SANCHEZ FREYRE, J.M., «La mayoría de edad como requisito para la rectificación registral del sexo y el nombre: una cuestión de derechos fundamentales», Revista sobre la infancia y la adolescencia, núm. 14, abril 2018, pp.39-52.
} 
(AC/2015/363)] se desestima la pretensión de los progenitores. Mediante Auto de 23.9.2015 (JUR/2015/229900) el TS admite a trámite el recurso extraordinario interpuesto por infracción procesal y de casación, dando lugar posteriormente al Auto de 2016 que comentamos.

El TS analiza en su Auto por un lado, toda la evolución jurisprudencial en relación con la solicitud de rectificación de la mención del sexo y cambio de nombre de las personas transexuales (FD 2..$^{\circ}$ ), así como el tratamiento de la cuestión por el TEDH y TJUE en relación con la vulneración del art. 8 del Convenio Europeo de Derechos Humanos (FD 3. ${ }^{\circ}$ ). Igualmente se centra en el estudio de las Resoluciones, Recomendaciones e Informes de las Instituciones Internacionales o Supranacionales sobre el reconocimiento de la transexualidad. Y específicamente en relación con los menores se centra tanto en el Informe sobre Derechos Humanos e Identidad de género del Comisario de Derechos Humanos del Consejo de Europa de 29 de julio de 2009 como en la ya citada Resolución 2048 de la Asamblea Parlamentaria del Consejo de Europa de 22 de abril de 2015 (FD 4. ${ }^{\circ}$ ).

Para el TS el tratamiento jurídico de la transexualidad es consecuencia directa del principio de respeto a la dignidad de la persona y al libre desarrollo de la personalidad (art. 10.1 CE), del derecho a la integridad física y moral (art. $15 \mathrm{CE}$ ), del derecho a la intimidad (art. 18.1 CE) y del derecho a la protección de la salud (art. $43 \mathrm{CE}$ ).

El Alto Tribunal culmina (FD $7^{\circ}$ ) manifestando sus dudas sobre la constitucionalidad del art. 1 de la Ley 3/2007 al exigir de la mayoría de edad para solicitar el cambio de la mención registral del sexo y el nombre en el Registro Civil considerando que «los menores no son ajenos a la problemática de las personas transexuales. En ellos, a los problemas que atañen a las personas transexuales en general se añaden los que son inherentes a la etapa de la infancia y la adolescencia». Por ello resuelve planteando la Cuestión de inconstitucionalidad tomando en consideración el reconocimiento de tales derechos a los menores atendiendo a dos elementos esenciales como son la progresiva madurez del menor en su evolución hacia el estado adulto, así como el principio de proporcionalidad.

2. La Instrucción de la DGRN de 23 de octubre de 2018 (BOE núm. 257, de 24 de octubre) sobre cambio de nombre en el Registro Civil de las personas transexuales

La DGRN da entrada en esta Instrucción al posible cambio de nombre en el Registro Civil de personas transexuales, tanto mayores como menores de edad, aunque no se cumplan los requisitos exigidos por el art. 4 de la Ley 3/2007, resultando suficiente con la manifestación de voluntad por parte del transexual sobre su propia identidad de género sentida como tal.

Por ello la citada Instrucción, aunque no alcanza más que a uno de los aspectos que venimos comentando en relación con las personas transexuales como es el del cambio del nombre, altera sustancialmente el contenido de lo señalado hasta ahora en nuestro trabajo, en la medida en que establece una serie de directrices para orientar la actuación de los en- 
cargados del Registro Civil ante la solicitud de cambio de nombre para la imposición de uno correspondiente al sexo diferente al que resulte de la inscripción de nacimiento (incluyendo en las mismas no solo a los menores de edad - para quién en definitiva se pensó inicialmente la Instrucción- sino también a los mayores de edad). Conforme a la misma se establece:

«Primero. En el supuesto de que un mayor de edad o un menor emancipado solicitara el cambio de nombre, para la asignación de uno correspondiente al sexo diferente del resultante de la inscripción de nacimiento, tal solicitud será atendida, con tal de que ante el encargado del Registro Civil, o bien en documento público, el solicitante declare que se siente del sexo correspondiente al nombre solicitado, y que no le es posible obtener el cambio de la inscripción de su sexo en el Registro Civil, por no cumplir los requisitos del art. 4 de la Ley 3/2007, de 15 de marzo, reguladora de la rectificación registral de la mención relativa al sexo de las personas.

Segundo. Los padres de los menores de edad, actuando conjuntamente, o quienes ejerzan la tutela sobre los mismos, podrán solicitar la inscripción del cambio de nombre, que será atendida en el Registro Civil, con tal de que ante el encargado del Registro Civil, o bien en documento público, los representantes del menor actuando conjuntamente declaren que el mismo siente como propio el sexo correspondiente al nombre solicitado de forma clara e incontestable. La solicitud será también firmada por el menor, si tuviera más de doce años. Si el menor tuviera una edad inferior, deberá en todo caso ser oído por el encargado del Registro Civil, mediante una comunicación comprensible para el mismo y adaptada a su edad y grado de madurez».

Sirva como primera reflexión que la DGRN al permitir la rectificación del nombre en el Registro Civil, tanto a mayores como a menores de edad transexuales, da, desde el punto de vista del reconocimiento de los derechos de las personas LGTBI un paso relevante, diríamos además que un paso «de gigante» en consonancia con las exigencias sociales (avaladas por el posicionamiento del TS como acabamos de ver más arriba) al no solo permitir a los menores de edad la rectificación registral de su nombre en el Registro, sino también y además, en la misma línea que venimos comentando, a los mayores de edad aunque no cumplan los requisitos legales previstos en el art. 4 de la Ley 3/2007 para acceder al cambio de sexo y por tanto dentro de la valoración del derecho del individuo al reconocimiento de su propia identidad de género sentida y manifestada al margen de las exigencias de proceso alguno de transformación física y tratamiento médico y hormonal. Es decir, prescindiendo de la exigencia del cumplimiento de los requisitos del art. 4 de la Ley 3/2007, así como de los requisitos de la LRC para proceder a la inscripción del cambio de nombre en el Registro.

Tal planteamiento ciertamente es acorde con la filosofía de los más recientes textos legales aprobados en las Comunidades Autónomas en materia de Igualdad de Género, de Derecho a la Identidad de Género y de protección de las personas LGTBI que veremos 
posteriormente y que despatologizan formalmente el tratamiento de la transexualidad e incluyen en el ámbito de su regulación a los menores de edad. De la misma manera se sincroniza con la normativa de otros ordenamientos europeos y del resto del mundo que han incorporado leyes de Identidad de Género despatologizantes e inclusivas en algunos casos de los menores de edad, con ciertas matizaciones en función de la edad concreta de los menores que han de ser tomadas en consideración cara a una futura regulación en España ${ }^{41}$.

Ahora bien, frente a dichos ordenamientos extranjeros ha de resaltarse lo evidente: no es en España el legislador quién lo hace, sino la DGRN a quien no le corresponde legislar y que además, nos guste o no, altera sustancialmente la interpretación y sentido de la normativa vigente (LRC 1957 y RRC 1958) en materia de determinación y cambio de nombre, así como de la LRC 2011(aunque ésta, en lo referente a la determinación del nombre y cambio del mismo no entrará aún en vigor, de momento hasta 2020).

Se altera claramente también lo dispuesto en la Ley 3/2007 en la medida en que para que los transexuales mayores de edad cambien no solo su sexo sino también su nombre, se requiere el cumplimiento de determinados requisitos de los que se prescinde en la Instrucción citada. Dicho de otra forma, la DGRN emite una Instrucción «contra legem» en la medida en que permite que los Registradores interpreten la ley de una forma distinta a lo

41 Es el caso de la legislación Argentina de 2012, citada anteriormente, que legitima a los menores de edad a través de sus representantes legales con conformidad expresa del menor atendiendo a la «capacidad progresiva del menor» y al interés «superior del menor» conforme a la Convención de D. del niño y a la Ley 26.061 de protección integral de los derechos de niñas, niños y adolescentes. Se prevé la asistencia del abogado del niño conforme al art. 27 de la Ley 26.061. Ante la ausencia de los consentimientos de los representantes: posible vía sumarísima para resolver judicialmente. Prevé igualmente la posibilidad de una nueva rectificación registral, pero en este caso mediando la autorización judicial correspondiente (ex art.8).

En el caso de Chile, tras un largo proceso legislativo de debate sobre el Proyecto de Ley de 7 de mayo de 2013 de Igualdad de Género, la Ley ha pasado el control de constitucionalidad el pasado 25 de octubre de 2018. Finalmente se legitima a los adolescentes entre 14 y 18 años, que podrán hacer uso de esta legislación y solicitar el cambio de nombre y sexo registral ante un tribunal de familia, donde el o la adolescente deberá contar con el apoyo de, al menos, uno de sus representantes legales o tutores. Respecto a los adultos, que no cuenten con un matrimonio vigente, el requerimiento se podrá realizar ante el Registro Civil, con el acompañamiento de dos testigos. Mientras que los mayores de 18 años que estén casados, la solicitud deberá realizarse ante un tribunal de familia, donde serán citados ambos cónyuges. En el caso de que la solicitud sea acogida el juez terminará el matrimonio, por lo que los comparecientes, para todos los efectos legales, se entenderán como divorciados manteniendo así todos los derechos y deberes adquiridos antes. $<$ https://www.iguales.cl/proyectoley-identidad-genero-pasa-control-del-tribunal-constitucional-sin-modificaciones/ $>$ [Consultado el 02/11/2018]. En Europa, mencionaremos el caso de la Legislación Irlandesa, la Gender recognition bill (15.7.2015) $<$ http://www.oireachtas.ie/documents/bills28/acts/2015/a2515.pdf $>$, que reconoce legitimación a los menores a partir de los 16 años con procedimiento complejo y autorización parental y judicial. En el caso de la ya mencionada Ley de Malta de 2015, se reconoce legitimación a los menores de edad, que podrán acceder a todos los derechos establecidos por la ley. Se abre la opción de que el sexo o la identidad de género no conste en los documentos oficiales. Y por otro lado, las personas transexuales legalmente casadas mantendrán su estado civil aún cuando efectúen el cambio legal de su identidad de género, siendo el único caso en que será válido un matrimonio formado por personas del mismo sexo. En cuanto al procedimiento para rectificar el sexo por parte de los menores de edad, es posible presentar la solicitud ante el Juez (en procedimiento de Jurisdicción Voluntaria), por sus representantes o tutores, valorando la posición del menor atendiendo a su edad y madurez. 
que la propia ley dice. Insisto, aunque se esté totalmente de acuerdo con la solución, ésta no justifica los medios utilizados para ello ${ }^{42}$.

Ciertamente la Instrucción trata, como ya ha ocurrido en más ocasiones de las que serían deseables, de suplir la lentitud o falta de operatividad (¿o consenso?) del legislador en resolver sobre un tema de la trascendencia y relevancia que tiene el de la protección de los derechos más fundamentales de los menores transexuales, y entre ellos la posibilidad de identificarse conforme al género al que sienten pertenecer y no al que les corresponde desde su nacimiento. Y ciertamente la razón de ser de la propia Instrucción va en ese sentido, tal y como se pone de manifiesto en la propia justificación que la avala, pero la DGRN va más allá de la mera pretensión protectora inicial, en la medida en que extiende esa posibilidad de cambio de nombre a los mayores de edad transexuales para los que sí les resulta ahora y les resultaba aplicable una solución para el cambio de nombre, la de la normativa prevista en la Ley $3 / 2007$, conforme a la cual (así como conforme a la propia LRC aún vigente) ya podían cambiar su nombre, pero reuniendo los requisitos exigidos por lo previsto en la citada normativa. Directamente para el cambio de nombre se prescinde de lo que la Ley exige.

La DGRN, con esta Instrucción va mucho más allá de lo que parece pretender ${ }^{43}$ : la posibilidad del cambio de nombre. Ello es así porque da un giro copernicano en la interpre-

42 En este sentido, claramente crítico con la Instrucción, se manifiesta BERCOVITZ RODRÍGUEZ-CANO, que directamente considera que en dicha Instrucción: «...se ordena a los encargados del Registro Civil, que incumplan tanto la Ley 3/2007 como la Ley de Registro Civil, en aras de lo que sería una regulación mejor para facilitar la modificación del nombre de las personas transexuales en el Registro Civil. Pero esa labor le corresponde al legislativo y no al Ministerio de Justicia... Ni la realidad social ni los principios constitucionales sirven para derogar la Ley si no lo declara el Tribunal Constitucional, que por ello ha sido calificado de legislador negativo...». BERCOVITZ RODRÍGUEZ-CANO, R., «Personas transexuales y estado de derecho" Revista Doctrinal Aranzadi Civil-Mercantil, núm. 11, tribuna, 2018 (BIB 2018/13976).

43 Va mucho más allá aparentemente, pero no prevé las consecuencias (los aspectos colaterales a los que últimamente solemos aludir en nuestros trabajos) que pueden derivarse de una solución parcial del problema que no toma en consideración los efectos colaterales que puedan ir vinculados a ello. Sobre todo porque, erróneamente desde nuestro punto de vista, se llega a afirmar que en definitiva, frente a la alegada razón de seguridad jurídica para impedir el cambio de nombre en estos casos en los que existe una contradicción con el sexo al que el nombre se corresponde no existe tal cuestión porque en definitiva la identificación real de la persona se produce a través del DNI y así se afirma que

«... [e]llo, sin embargo, no parece argumento suficiente para impedir la inscripción de un nombre que se corresponda con el sexo sentido por la persona. Por una parte, no puede alegarse que con ello se pueda dar lugar a confusiones, intencionadas o no, en la identificación de la persona: debe observarse, a este respecto, que el principal elemento identificador de la persona, por su eficacia para evitar errores y duplicidades, es el número del DNI (cuyo uso en la actualidad goza de una consolidación y controles muy superiores a los que se daban en el año 1957), que se hará constar en el asiento registral correspondiente, y que precisamente esa virtualidad identificadora del DNI permite muchos otros cambios de apellidos y de nombre, sin mayores problemas...)». (Exposición de motivos de la Instrucción de 23.10.2018 (BOE núm. 257 de 24.10.2018, p. 103343).

Tenemos serias dudas sobre los problemas que pudieran plantearse, sea por ejemplo fuera de nuestras fronteras, para la identificación de una persona con dicha discordancia, tomando como base las afirmaciones que la DGRN realiza al respecto). 
tación de lo que hasta ahora se ha venido predicando legalmente en cuanto a las exigencias para proceder al cambio de sexo (y consecuentemente al cambio de nombre en tales casos), esto es, la consideración de la transexualidad como una patología que requiere de un previo tratamiento médico para proceder a tal modificación. Conforme a la citada Instrucción sin embargo, parece atenderse a la propia voluntad del o la transexual, a su propia manifestación de voluntad derivada de un sentimiento personal, íntimo y propio de pertenecer a un género diferente al asignado en el momento del nacimiento, vinculado con lo cual va indefectiblemente ligado el derecho a identificarse y ser identificado con un nombre ${ }^{44}$.

Dicho esto no deja de preocuparnos el hecho de que sea una Instrucción la que, sin entrar en matices que pueden plantear problemas posteriormente ${ }^{45}$, proceda a enmendar al legislador permitiendo lo que este no permite, por muy adecuado, necesario y exigible que sea permitir la rectificación registral del nombre y, en su caso, del sexo de las personas aún siendo menores de edad e incluso sin necesidad de consideración médica alguna. Es una solución que puede predicarse como «parche momentáneo» hasta tanto no se legisle y modifique la Ley $3 / 2007$ pero que claramente resulta contradictorio con lo dispuesto en la LRC, RRC y la Ley 3/2007 que no solo alude a la rectificación registral del sexo de las personas sino a la del nombre de la persona como consecuencia de la citada rectificación.

\section{Las Proposiciones de Ley de 2017 y 2018 que afectan a los artículos 1 y 4 de la Ley} 3/2007, despatologizantes e inclusivas de los menores de edad

Junto con las Resoluciones y Proposiciones no de Ley que mencionábamos en otro momento de nuestro trabajo es importante resaltar que en un solo año tres han sido las Proposiciones de Ley presentadas en el Congreso que de forma directa o indirecta plantean la modificación de la Ley $3 / 2007$, reguladora de la rectificación registral de la mención relativa al sexo de las personas con la finalidad de conferir legitimación a los menores para rectificar registralmente su sexo y para modificar las exigencias establecidas en el art. 4 de la misma relativas a los requisitos previos para acordar la rectificación.

44 Vid., en tal sentido, la interrelación que se pone de manifiesto entre el derecho al nombre y a la identidad personal en BENAVENTE MOREDA, P., «Identidad y contexto inmediato de la persona (identidad personal, el nombre de la persona, identidad sexual y su protección)», AFDUAM, núm. 17, 2013, pp. 108-116. Como ya indicamos en dicha publicación, el derecho al nombre como forma de identificación de la persona es objeto de protección en el ámbito del art. 8 del Convenio Europeo de Derechos Humanos como manifestación de la identidad personal del individuo.

45 ¿Se podrá cambiar de nombre varias veces? ¿Existe algún tipo de limitación al respecto? Esta es tan solo una de las cuestiones que podemos plantearnos. Ciertamente al leer el contenido de la Instrucción da la sensación de que el Centro Directivo confía excesivamente en que el legislador de inmediato dé salida a las diferentes Proposiciones de Ley que se debaten en el Congreso en los momentos en que se redacta este documento. Tal confianza parece delegar al legislador (al que por otro lado, no olvidemos, es al que le corresponde alterar en contenido de los textos legales, por mucha premura que requiera solucionar el problema existente) la solución de las cuestiones puntuales que deberán afrontarse al permitir el cambio de sexo y nombre de los menores transexuales. Cuestiones que se abordan precisamente en alguna de las Proposiciones de Ley en debate. 
La primera de las Proposiciones de Ley es la 122/000072 presentada por el Grupo Parlamentario Socialista en el Congreso, de 3 de marzo de 2017 (BOCG, serie B. Núm. 91-1-pp.1-4). El sentido directo de la Propuesta se indica en su exposición de motivos que la justifica con una triple finalidad:

«para permitir la rectificación registral de la mención relativa al sexo y nombre de los menores transexuales y/o trans, para modificar las exigencias establecidas en el artículo 4 -suprimiendo la obligación de aportar o acreditar cualquier tipo de documentación médica, ni haberse sometido a cirugías genitales ni de ningún otro tipo o terapias hormonales-, y para posibilitar el cambio de sexo y nombre en la tarjeta de residencia, permiso de trabajo que les haya sido expedido a las personas extranjeras cuando se cumplan determinados requisitos, así como el reconocimiento del cambio de sexo registral de las personas intersexuales».

En lo que nos interesa específicamente en este trabajo cabe resaltar que se propone la modificación del art. 1 de la Ley 3/2007 para legitimar a los menores de edad para solicitar la rectificación registral de su sexo. Los mayores de 16 años podrían solicitarla por sí mismos mientras que los menores de dicha edad e incapacitados legalmente actuarían a través de sus progenitores o representantes legales con expresa conformidad del menor. En caso de oposición de uno o ambos progenitores o representante legal los menores de edad podrán solicitarlo a través del Ministerio Fiscal, resolviendo el Juez en proceso de jurisdicción voluntaria, y debiendo adoptar la decisión siempre atendiendo al interés superior del menor.

Igualmente se propone la modificación del art. 4 para suprimir, en la línea de despatologizar el tratamiento de la transexualidad, la exigencia del cumplimiento de los requisitos previos mencionados en dicho precepto, siendo suficiente con la declaración expresa de la persona interesada del nombre propio y sexo registral con los que se siente identificado. Lo que implica un reconocimiento directo del valor de la autonomía de la voluntad tanto del mayor como menor de edad para definir la propia identidad conforme al sentimiento de identidad propio ${ }^{46}$.

46 Dentro de las enmiendas presentadas a la Proposición (BOCG, Serie B-núm. 91-4, p.4, 21.3.2018), convendría hacer referencia al contenido de algunas de ellas (que a la fecha de cerrar este trabajo aún se desconoce si prosperarán o no). Tal es el caso de la núm. 4 presentada por el propio Grupo Parlamentario Socialista, que propone la adición al propuesto apartado $1 \mathrm{del}$ art. 4 de un segundo apartado conforme al cual se establece que «La persona interesada podrá solicitar que figure en blanco la mención relativa al sexo de su inscripción de nacimiento si no se siente identificada con ninguna categoría; teniendo derecho, asimismo, a que figure en la misma forma en sus documentos de identidad». La justificación de tal enmienda se encuentra en la intención de poner de manifiesto la protección legal frente al binarismo establecido tradicionalmente, para permitir la protección de una realidad, que aunque minoritaria, también tiene derecho a ser tenida en cuenta, sin que se pueda obligar a hacer constar registralmente como hombre/mujer a quien no se identifica como tal. La enmienda, se apunta, beneficiaría a muchas personas trans que aún están en proceso de transición, a las personas intersexuales que pueden identificarse como hombres y mujeres, y a las personas que se identifican de manera diferentes, como el género fluido o sin género. Así pues, la concepción del sexo como «estado civil» 
La propuesta nada incluye sobre las posibilidades futuras de nuevas rectificaciones, sus límites y condicionantes en su caso, como hacen expresamente otros ordenamientos jurídicos como el argentino por ejemplo ${ }^{47}$.

La segunda propuesta, presentada dos meses después de la anterior ${ }^{48}$ se trata de la Proposición de ley 122/000097 contra la discriminación por orientación sexual, identidad o expresión de género y características sexuales, y de igualdad social de lesbianas, gais, bisexuales, transexuales, transgénero e intersexuales, presentada por el Grupo Parlamentario Confederal de Unidos Podemos, En Comú Podem y En Marea, el 12 de mayo de 2017 (BOCG, serie B, núm. 122-1 de 12 de mayo) ${ }^{49}$.

La estructura de la Propuesta es más ambiciosa que la anteriormente citada, en la medida en que no solo propone expresamente la modificación de los arts. 1 y 4 de la ya citada Ley $3 / 2007$, en un sentido parecido a la presentada por el Grupo Socialista, sino que, siguiendo la estela de las leyes de Identidad de Género o protectoras de las personas LGTB en las CCAA regula otros aspectos colaterales vinculados directamente con la intención protectora de las personas LGTBI.

Dicho esto resaltaremos aquí tan solo algunos de los aspectos que, relacionados con el tema específico que nos ocupa, conviene poner de manifiesto:

pasa a un segundo plano, por detrás de la protección de los derechos fundamentales. Se sigue por tanto con este propósito la estela de ordenamientos como el alemán o el argentino tal y como hemos puesto de manifiesto anteriormente, al permitir, bien la existencia de «otras manifestaciones de la sexualidad no binarias» o incluso la ausencia de encaje en uno u otro sexo. Igualmente interesante resulta la enmienda núm. 10, presentada por el Grupo Parlamentario Popular en el Congreso, conforme a la cual se propone la modificación del apartado 2 del art. 1 de la Propuesta para dar mayor protección a los menores mayores de 16 años, proponiendo al respecto que: «[1]as personas mayores de 16 años podrán efectuar la solicitud por sí mismas, previo conocimiento de sus padres o representantes legales. En caso de constar oposición de uno o ambos progenitores, podrán efectuar la solicitud a través del Ministerio Fiscal de acuerdo con el apartado 4 de este artículo». Justificando su propuesta en el hecho de considerar que se garantiza tanto a los menores de edad como a las personas con la capacidad de obrar modificada legalmente una mayor protección.

47 Según el art. 8 de la Ley de Identidad de Género núm. 26.743 de 2012, una vez realizada la rectificación registral conforme a dicha Ley, solo podrá ser nuevamente modificada con autorización judicial.

48 Lo que pone de manifiesto la falta de acuerdos y consensos entre los grupos parlamentarios, que a nuestro entender conduce, como no es la primera vez que ocurre, a la existencia final de contradicciones entre textos legales que parecen a veces discurrir en paralelo como en mundos diferentes. Basta con comparar el texto de las propuestas para darse cuenta de que a veces podrían conciliarse posiciones partidistas para llegar a un texto legislativo que, en cuanto nos interesa, tenga coherencia legal con otras normas vinculadas.

49 En los momentos actuales la Proposición se encuentra en fase de Informe en la Comisión de Igualdad del Congreso de los Diputados desde el 28 de febrero de 2018. $<$ http://www.congreso.es/portal/page/portal/ Congreso/Congreso/Iniciativas?_piref73_2148295_73_1335437_1335437.next_page=/wc/servidorCGI\&CM $\mathrm{D}=\mathrm{VERLST} \& \mathrm{BASE}=\mathrm{IW} 12 \& \mathrm{FMT}=\mathrm{INITXDSS} . \mathrm{fmt} \& \mathrm{DOCS}=1-\overline{1} \& \mathrm{DOCORDER}=\mathrm{FIFO} \& O P D E F=\mathrm{ADJ} \& Q U E$ $\mathrm{RY}=\% 28122 \% 2 \mathrm{~F} 000097 *$.NDOC.\%29>. [Consultado el 01/11/2018]. En cualquier caso, sobre la Proposición de Ley se han presentado 287 enmiendas que tendrán que ser objeto de debate en su momento. Vid. BOCG núm. 122-4, de 22.3.2018. 
- Tal es la vertiente despatologizadora de la Propuesta que se recoge en su art. 20.3, dentro de los principios rectores de la atención sanitaria de las personas transexuales y transgénero:

«La atención sanitaria se basará en una visión despatologizadora, es decir, en la consideración de que la vivencia transexual y transgénero no es una enfermedad, un trastorno o anomalía, sino que forma parte de la diversidad humana. Los profesionales de la salud realizarán un acompañamiento de la persona en el desarrollo de su identidad sentida. Estará vetada cualquier prueba, exploración o test psicológico o psiquiátrico para determinar la condición de persona transexual o transgénero, así como cualquier práctica médica que limite o coarte esta libertad».

Esta vertiente se sitúa en la línea de protección del derecho al libre desarrollo de la personalidad ex art. $7.1 \mathrm{~b}$ ), conforme al cual la Ley se inspira precisamente y entre otros en

«el derecho al libre desarrollo y reconocimiento de la personalidad que incluye el derecho de cada persona a construir su propia autodefinición con respecto a su cuerpo, sexo, género y su orientación sexual y a ser tratada con respecto a la misma. La orientación sexual e identidad de género forman parte de los derechos personalísimos que se basan en los derechos fundamentales a la dignidad y a la libertad. Ninguna persona podrá ser presionada para ocultar, modificar o negar su orientación sexual, expresión o identidad de género».

- La Proposición de acceso a los menores de edad al proceso de rectificación sexual, permitiendo a partir de los 16 años prestar por sí mismos el consentimiento informado para acceder a la reasignación sexual quirúrgica. Y a partir de la pubertad podrán prestar por sí mismos el consentimiento informado para acceder a los bloqueadores hormonales y al tratamiento hormonal cruzado (art. 20 bis 2).

- Se establece un protocolo en materia de intersexualidad, velando por la erradicación de las prácticas de reasignación sexual de los recién nacidos, salvo indicaciones médicas para proteger la salud del recién nacido (art. 21).

- Se establece igualmente un sistema especial de protección en el ámbito educativo (Cap. VII) recogiendo expresamente el derecho a la identidad sexual y de género (art. 44) y la posibilidad de exteriorizar el género sentido como cauce de identificación administrativa en censos, calificaciones, listados conforme al nombre elegido por alumnos y profesores. Lo mismo en el seno de las Universidades (art. 46). 
- Dentro de las medidas en el ámbito de la infancia y la juventud (Cap. IX) se reconoce «el derecho de los y las menores a desarrollarse física, mental y socialmente de forma saludable plena, así como en condiciones de libertad y dignidad. Ello incluye la autodeterminación y el desarrollo evolutivo de su propia identidad y expresión de género y el derecho a utilizar libremente el nombre que hayan elegido» (art. 52).

- Igualmente y como ya lo han hecho muchas de las CCAA que han regulado la materia, dentro del ámbito de sus competencias, la Proposición de Ley dedica su Capítulo XVIII a las Transidentidades e Intersexualidad, reconociendo el derecho humano a la autodeterminación de la identidad de género sin injerencias ni discriminaciones (art. 76), así como al reconocimiento de su identidad de género libremente determinada y a ser tratadas conforme a la misma, con independencia de haber obtenido o no su reconocimiento legal (art. 77). Igualmente se establece el derecho a que quede determinada la identidad de la persona en todos los documentos que la deban acreditar, lo que se desarrollará, según se establece, reglamentariamente (art. 85).

Por último y muy brevemente deberíamos hacer referencia a una Proposición de Ley, que aún retirada del debate en el Congreso, conviene traer a colación para evidenciar lo que se ha venido indicando en relación con la posible desconexión de los diferentes (y en este caso los mismos) grupos parlamentarios en el Congreso, que ponen de manifiesto el desgaste de esfuerzos mal canalizados que posteriormente sirven para que a la postre puedan existir textos legales desconexos. Se trata de la Proposición de ley 122/000191 sobre protección jurídica de las personas trans y el derecho a la libre determinación de la identidad sexual y expresión de género, presentada igualmente por el mismo Grupo Parlamentario Confederal de Unidos Podemos, En Comú Podem y En Marea, de 2 de marzo de 2018 (BOCG, serie B, núm. 220-1, de 2.3.2018).

En cuanto nos interesa poner de manifiesto del contenido de dicha proposición, sería destacable el hecho de regular nuevamente aspectos abordados en la Proposición de Ley anterior del mismo grupo parlamentario, así como las abordadas en la Proposición presentada en 2017 por el Grupo Parlamentario Socialista en relación con la posibilidad de rectificación del nombre y sexo de las personas transexuales, incluso en la minoría de edad (art. 7) dentro del ejercicio del derecho de autodeterminación, permitiendo el acceso a partir 16 años (art. 7.1) y antes de dicha edad atendiendo a su madurez (capacidad intelectual y emocional de comprender el alcance de dicha decisión) o por sus representantes legales tras haber escuchado su opinión conforme a lo dispuesto en el art.9 LOPJM. Establecía igualmente (de forma diferente a la propuesta del PSOE) que en caso de discrepancia con uno de los progenitores o representantes del menor, le correspondería al otro adoptar la decisión correspondiente y, en caso de discrepancia de ambos con el menor, se le nombraría a este un defensor judicial (art. 7.3). 
Por otro lado se proponía igualmente, en la línea de las anteriores proposiciones, la despatologización en el tratamiento de la transexualidad para proceder al cambio de sexo, no siendo necesario para solicitarlo la previa exhibición de informe médico o psicológico alguno, ni la previa modificación de la apariencia o función corporal de la persona a través de procedimientos médicos, quirúrgicos o de otra índole, sin perjuicio del derecho de las personas trans a hacer uso de dichos medios (art.7.4).

\section{Normativa Autonómica sobre la materia a través de las diferentes Leyes de Identidad de género o reguladoras de los derechos de las personas LGTBI}

Dedicaremos este último apartado a analizar brevemente la posición mantenida por las Comunidades Autónomas que mayoritariamente y ante la falta de respuesta del legislador estatal, han venido legislando, teóricamente en el ámbito de sus respectivas competencias, sobre los derechos de las personas LGTBI a través de normas protectoras apoyadas esencialmente en el derecho al libre desarrollo de su personalidad y en la idea, común a la mayoría de los textos existentes, del reconocimiento del derecho del individuo a identificarse conforme al propio sentimiento de identidad de género sentido al margen del sexo asignado en el momento del nacimiento ${ }^{50}$.

Común a la mayoría de las normas a las que nos referiremos es, por un lado, el reconocimiento de los menores de edad a su propia identidad, conforme al sentimiento personal de género y al margen de la existencia de tratamientos y valoraciones médicas o psiquiátricas y psicológicas. La posibilidad (en los textos legales aprobados en la última década mayoritariamente) de que los transexuales, mayores o menores de edad, puedan identificarse, en el ámbito de las competencias de las propias CCAA, conforme al género sentido creando la posibilidad de expedir documentación administrativa propia y al margen de la identificación registral de la persona conforme a la normativa general prevista en la LRC.

Igualmente coincidente en la mayoría de los textos legales autonómicos es prescindir de la calificación de la transexualidad dentro del ámbito de las patologías, para hablar más de la «identidad de género» como sentimiento personal e íntimo de ser de otro sexo diferente

50 ALBENTOSA DEL RIO ya manifestó la relevancia de la normativa autonómica, precisamente por el hecho de ser ésta la que abordaba por primera vez la situación de los menores transexuales, ob.cit., pp.159164. Además de lo indicado la relevancia de la regulación autonómica también se encuentra en el hecho de que una parte significativa de las cuestiones que afectan a las personas transexuales es objeto de competencia autonómica. Vid. ELVIRA PERALES, A. «Transexualidad y derechos», ob. cit., p.25. No obstante, autores como PLATERO MÉNDEZ se manifiestan críticos con la posición legislativa de las CCAA al respecto ante la ausencia de protocolos comunes de atención a menores y jóvenes trans lo que crea un claro panorama muy heterogéneo, sobre todo teniendo en cuenta que la legislación estatal sobre la materia, ante la ausencia de una ley integral, dice muy poco sobre la intervención psicosocial de los menores, regulando tan solo el acceso a la cirugía para los mayores de edad. Vid. PLATERO MÉNDEZ, R., Transexualidades. Acompañamiento, factores de salud y recursos educativos, ob. cit., p.173. 
al asignado con el nacimiento, que permite crear una identidad administrativa (a efectos sanitarios, educativos, culturales, deportivos...) de cada individuo.

Común igualmente a las más recientes normativas es el abordar dentro de los propios textos legales normas específicas destinadas al tratamiento de la intersexualidad, con la finalidad y encomienda específica de evitar intervenciones médicas tempranas destinadas a definir el sexo de los menores en el momento del nacimiento en aquellos supuestos en los que no quede determinado de manera clara el sexo del nacido.

En todo caso se analizarán aquí exclusivamente los aspectos relacionados con el criterio seguido por cada normativa en materia de determinación de la identidad de los menores de edad, pero no entraremos en el análisis de los aspectos colaterales objeto de regulación en cada una de las leyes autonómicas (cuestión que será abordada por nosotros en un trabajo más amplio que monográficamente se dedicará al tema).

\section{A. Normativa autonómica sobre Identidad de Género y derechos de personas LGTBI}

Hasta el momento son doce las Comunidades Autónomas que, desde 2009 han legislado sobre los derechos de las personas LGTBI o sobre la Identidad de Género ${ }^{51}$. Prácticamente tras la aprobación de la Ley 3/2007 y en apenas una década el legislador autonómico ha venido a intentar suplir, como ha ocurrido en otras muchas ocasiones, la falta de actividad del legislador nacional, creando, desde nuestro punto de vista, algunas discordancias que en algunos momentos han planteado problemas efectivos de debate sobre la posible ausencia de competencia legislativa autonómica sobre la materia abordada, además de plantear, desde nuestro punto de vista, en algunos casos concretos, dudas sobre la creación de un doble sistema de identificación de la persona al margen de la prevista a través de la Ley Registro Civil, diferenciándose de manera un tanto artificial entre identidad registral e identidad administrativa. Ello fundamentalmente porque si bien en la normativa autonómica se perfila el derecho a identificarse incluso documentalmente, como venimos señalando, conforme a la identidad de género sentida, no ocurre otro tanto a nivel estatal dentro del ámbito de la legislación que regula el sistema de inscripción en el Registro Civil

51 En los momentos de redactar este trabajo se encuentran en debate además leyes específicas en otras cuatro Comunidades Autónomas: El Proyecto de Ley de garantía del derecho a la libre expresión de la identidad sexual y/o género, de Asturias de 23.11.2018((10/0142/0030/27998)(BOJPA 28.11.2018.n $\left.{ }^{\circ} .111 .1\right)$; en Cantabria el Proyecto de Ley de garantía de derechos de las personas lesbianas, gais, transexuales, transgénero, bisexuales e intersexuales y no discriminación por razón de orientación sexual e identidad de género, de5.11.2018(BOC 5.11.2018, no 426, p.12414); en Castilla y León la Proposición de Ley ( PPL/000018-01) de igualdad social de la diversidad sexual y de género, y de políticas públicas contra la discriminación por orientación sexual e identidad de género de la Comunidad de Castilla y León, de 15 de marzo de 2018 (BOCCYL n³92 de 23.3.2018, pg.51616) y en La Rioja la Proposición de Ley de no discriminación de identidad de género y de reconocimiento de los derechos de las personas transexuales de 24 de mayo de 2017 (BOPLR 24.5.2017). 
relativa al sexo y nombre de las personas, lo que crea una situación cuanto menos confusa que debe resolverse de inmediato en el ámbito estatal.

La primera en legislar fue la Comunidad Navarra, que aprobó la Ley foral de Derechos de los transexuales de 19 de noviembre de 2009 (BOPN núm.147, 30.11.2009, p.15135) y posteriormente la Ley Foral 8/2017 de 19 junio para la igualdad de las personas LGTBI+ (BOE, núm. 137, 21.7.2017, p. 63642).

País Vasco aprobó la Ley de derechos de las personas transexuales el 28 de junio de 2012(BOPV núm. 132, 6.6.2012, p. 3067); Galicia, la Ley 2/2014, de 14 de abril, por la igualdad de trato y la no discriminación de lesbianas, gays, transexuales, bisexuales e intersexuales (BOE núm. 127, 26.5.2014, p. 39758).

Andalucía dio un paso más en cuanto al contenido y reconocimiento de los derechos de los menores trans al aprobar su Ley integral $2 / 2014$, de 8 de julio, para la no discriminación por motivos de identidad de género y reconocimiento de los derechos de las personas transexuales. (BOJA núm. 139, 18.7.2014), para posteriormente aprobar la Ley 8/2017, de 28 de diciembre para garantizar los derechos de la igualdad de trato y no discriminación de las personas LGTBI y sus familias (BOJA núm. 10, 15.1.18, p.12).

A dicha normativa siguieron con carácter igualmente protector de los derechos de los menores y con tendencia despatologizadora las leyes de Cataluña, Ley 11/2014, de 10 de octubre, para garantizar los derechos de lesbianas, gays, bisexuales, transgéneros e intersexuales y para erradicar la homofobia, bifobia y transfobia (BOE 20.11.2014, p. 94729), la de Canarias, Ley 8/2014, de 28 de octubre, de no discriminación por motivos de identidad de género y de reconocimiento de los derechos de las personas transexuales (BOE 20.11.2014, p. 94850) o la extremeña Ley 12/2015, de 8 de abril, de libertad sexual (BOE núm. 108, 6.5.2015, p. 39518).

Especial relevancia ofrece la normativa aprobada en la Comunidad de Madrid, siguiendo la estela de la legislación andaluza, a través de dos leyes específicas, como son la Ley $2 / 2016$, de 29 de marzo, de identidad y expresión de género e igualdad social y no discriminación (BOE núm. 169, 14.7.2016, p. 49217) ${ }^{52}$ y la Ley 3/2016, de 22 de julio, de

52 En relación con la primera de las Leyes aprobadas en la Comunidad de Madrid ha de tenerse en cuenta la Resolución de 14 de febrero de 2017 (BCM núm. 50, de 28.2.2017, pp.39) en que se publica el Acuerdo de 17 de enero de 2017 de la Comisión Bilateral de Cooperación entre la Administración General del Estado y la Comunidad de Madrid. Dicho Acuerdo se refería fundamentalmente a la interpretación que habría de darse a los arts. 7 y 48 de la Ley para constatar su constitucionalidad. El primero referido a la forma de identificación de las personas transexuales conforme a su género sentido, y el segundo referido a las normas procesales aplicables. Conforme al citado Acuerdo se señala los siguiente:

«1. De conformidad con las negociaciones previas celebradas por el Grupo de Trabajo constituido en cumplimiento de lo previsto en el Acuerdo de la Comisión Bilateral de Cooperación Administración General del Estado-Comunidad de Madrid de 23 de junio de 2016 para el estudio y propuesta de solución de discrepancias competenciales suscitadas en relación con los arts. 7 y 48 de la Ley 2/2016, de 29 de marzo, de Identidad y Expresión de Género e Igualdad Social y no Discriminación de la Comunidad de Madrid, ambas partes las 
Protección integral contra la LGTBIfobia y la Discriminación por Razón de Orientación e Identidad Sexual en la Comunidad de Madrid (BOE núm. 285, 25.11.2016, p.82459). Con contenido parecido a la primera de las leyes de la CM se desarrolla la normativa posteriormente aprobada en Comunidades como Murcia, a través de su Ley 8/2016, de 27 de mayo, de igualdad social de lesbianas, gays, bisexuales, transexuales, transgénero e intersexuales, y de políticas públicas contra la discriminación por orientación sexual e identidad de género (BOE núm. 153, 25.6.2016, p.45833), Islas Baleares, mediante Ley 8/2016, de 30 de mayo, para garantizar los derechos de lesbianas, gays, trans, bisexuales e intersexuales y para erradicar la LGTBI fobia (BOCAIB 2.6.2016) o la Ley 8/2017, de 7 de abril, de la Comunidad de Valencia, integral de reconocimiento del derecho a la identidad y expresión de género (DOGV 8019, 11.4.2017, p. 12310). Las últimas en aprobarse de momento, son la Ley de Aragón 4/2018, de 19 de abril, de identidad y expresión de género e igualdad social y no discriminación (BOE 7.5.2018) y la Ley 18/2018, de 20 de diciembre, de Igualdad y Protección integral contra la discriminación por razón de orientación sexual, expresión e identidad de género, también de Aragón (BOE 11.1.2019).

B. Derecho al reconocimiento de la Identidad sentida frente a la Identidad sexual registrada. ¿Conflicto de identidades administrativa vs registral? Inclusión y reconocimiento de los menores de edad

¿Cómo se aborda, en general en el ámbito de las CCAA el tema de la transexualidad de los menores de edad? Realmente hay que tener en cuenta que, por un lado, en la mayoría de los casos numerosas cuestiones quedan postergadas al desarrollo reglamentario posterior, pero en todo caso en la mayoría de los textos indicados se prevé la existencia de «documentación administrativa» correspondiente con la identidad de género (sexo al que sienten pertenecer) en el ámbito de las competencias autonómicas correspondientes (sanitaria, educación, cultura, deportes etc.). Se tiende igualmente al reconocimiento del «género sentido» al margen de tratamientos médicos y al margen de la consideración de las personas transexuales o transgénero como personas enfermas. Se tiende por tanto hacia la despatologización de la transexualidad.

consideran solventadas en razón de las consideraciones siguientes: Primera.-Ambas partes entienden que la expedición de la documentación a que se refiere el artículo 7 de la Ley debe entenderse exclusivamente a los efectos de la propia Ley y en el ámbito competencial de la Comunidad de Madrid, sin que afecte a la identidad jurídica del interesado, en tanto no se produzca la rectificación de la inscripción registral regulada en la Ley 3/2007, de 15 de marzo ( RCL 2007, 524 ), reguladora de la inscripción registral de la mención relativa al sexo de las personas. Segunda.-Ambas partes consideran que las reglas procesales contenidas en el artículo 48 de la Ley son las establecidas por la legislación procesal estatal, por lo que debe entenderse que su interpretación y aplicación se realizará en cualquier caso de conformidad con la legislación procesal estatal. 2. Comunicar este Acuerdo al Tribunal Constitucional, a los efectos previstos en el artículo 33.2 de la Ley Orgánica 2/1979, de 3 de octubre (RCL 1979, 2383), del Tribunal Constitucional, así como insertar el presente Acuerdo en el "Boletín Oficial del Estado" y en el Boletín Oficial de la Comunidad de Madrid...». 
No obstante el legislador autonómico, como no podría ser de otra forma al carecer de competencia para ello, no aborda el tema del cambio de sexo, lo que es objeto de tratamiento, como hemos visto, en una ley estatal, la Ley 3/2007. Ello no impide sin embargo que en la mayoría de las normas autonómicas se dedique un capítulo a la regulación de la «identidad» de las personas transexuales al margen del sexo asignado en el momento del nacimiento y por tanto previendo la posibilidad de ser identificadas mediante una documentación administrativa diferente de la registral para todas aquellas cuestiones en las que correspondiendo la competencia a la CCAA se exija la acreditación personal del individuo. Ello, como ya hemos manifestado a lo largo del trabajo, si bien parece una fórmula adecuada para provocar un cambio legislativo en la materia como ha puesto de manifiesto ya la DGRN a través de su Instrucción de 23 de octubre de 2018 a la que hicimos referencia más arriba, crea, desde nuestro punto de vista, un problema de «doble vía de identificación» (administrativa y registral), que puede plantear problemas a la larga en algo tan sensible como es el derecho a la propia identidad de la persona.

La Ley Andaluza del 2014 fue de las primeras que, siguiendo los criterios de legislaciones tan innovadoras como la Argentina, vino a definir la identidad de género como la vivencia interna e individual del género tal y como cada persona la siente profundamente, incluyendo la vivencia personal del cuerpo y otras como la vestimenta, el modo de hablar y los modales. La identidad de género está generalmente acompañada del deseo de vivir y recibir aceptación como miembro de dicho género e incluso del deseo invencible de modificar, mediante métodos hormonales, quirúrgicos o de otra índole, el propio cuerpo, para hacerlo lo más congruente posible con el sexo-género sentido como propio.

Así se define tanto en la Exposición de motivos como en el art. 3 de la Ley de 2014. Incluyendo por primera vez la posibilidad ya mencionada de expedición de documentación administrativa propia (art. 9) al objeto de ofrecer una mejor integración y evitar situaciones de sufrimiento, documentación a la que igualmente tienen acceso los menores de edad, de conformidad con lo dispuesto en su art. 19, específicamente destinado a la regulación de la protección de los menores, atendiendo siempre al interés superior del menor que hace primar en todas las actuaciones de la Administración ${ }^{53}$.

53 Prácticamente en todas las Comunidades se ha planteado el mismo problema y en relación con los mismos preceptos, relativos a la posible inconstitucionalidad de las Leyes autonómicas aprobadas. Así, con la Ley Andaluza el Gobierno llegó a un acuerdo, para no recurrir ante el TC la posible inconstitucionalidad de determinados preceptos sobre los que había discrepancia: los relativos a la concesión de documentación administrativa que refleje la «identidad de género manifestada» por las personas transexuales, así como el reconocimiento del derecho de los menores con disconformidad de su identidad de género a utilizar libremente el nombre por ellos elegido o la inclusión en la cartera básica de servicios sanitarios de determinados tratamientos médicos para realizar el cambio de sexo. El acuerdo, en cuanto nos interesa resaltar estableció que «una interpretación coincidente con la norma por la que se determina que "la disposición reglamentaria que establezca el procedimiento de acreditación velará porque se mantenga la debida separación entre el nombre del Registro Civil y el nombre elegido por razones de identidad de género, de tal forma que la acreditación de dicha identidad de género se entiende exclusivamente a los efectos de la propia Ley y en el ámbito competencial de la Comunidad Autónoma de Andalucía». El mismo problema se ha planteado, como hemos visto más arriba, 
Igual criterio sigue la normativa de la Comunidad de Madrid, que considera la identidad de género como la vivencia interna e individual del género tal y como cada uno la percibe, de lo que deriva, incluso para los menores de edad, el derecho al reconocimiento de la identidad vivida a efectos de tratamiento administrativo (art. 7) para el acceso a los servicios administrativos y de toda índole ${ }^{54}$.

Debemos destacar por último, en este breve recorrido por los aspectos más relevantes de la normativa autonómica, el hecho de que en prácticamente todas las legislaciones autonómicas de referencia recogen un título específico destinado al tema de la Intersexualidad, a la prohibición de las prácticas médicas invasivas que no tengan un carácter estrictamente necesario desde el punto de vista y la valoración profesional, y el rechazo a las intervenciones tempranas tendentes a definir el sexo de los recién nacidos intersexuales. Sirva de ejemplo el contenido del vigente art. 15 de la Ley de 29 de marzo de 2016 de la Comunidad de Madrid, conforme al cual se establece, dentro de las normas de Atención sanitaria a las personas intersexuales:

«1. El sistema sanitario público de Madrid velará por la erradicación de las prácticas de modificación genital en bebes recién nacidos atendiendo únicamente a criterios quirúrgicos y en un momento en el que se desconoce cuál es la identidad real de la persona intersexual recién nacida. Todo ello con la salvedad de los criterios médicos basados en la protección de la salud de la persona recién nacida y con la autorización legal.

2. Se procurará conservar las gónadas con el fin de preservar un futuro aporte hormonal no inducido. Incluyendo en los controles los marcadores tumorales.

3. No se realizarán pruebas de hormonación inducida con fines experimentales ni de otro tipo hasta que la propia persona o sus tutores legales, así lo requieran en función de la identidad sexual sentida.

en relación con la legislación madrileña y precisamente en relación con las mismas cuestiones, así como con la Legislación Valenciana y la del País Vasco. Y precisamente en relación con las mismas cuestiones suscitadas en el caso andaluz. Así en relación con la Legislación valenciana se ha llegado igualmente a un acuerdo sobre la posibilidad de una documentación que las personas trans puedan usar mientras no les es posible cambiar su identidad jurídica en el documento nacional de identidad. Así, el acuerdo entre las dos Administraciones establece la legalidad de esta documentación en el ámbito autonómico y municipal, lo que afecta a servicios como la educación, la sanidad o los trámites administrativos de carácter autonómico. Esto significa, que una persona trans que vaya al médico o se presente a un examen en un instituto podrá identificarse con esta documentación que contempla la ley autonómica, si bien esta documentación de carácter autonómico no podrá suplir al DNI. (información obtenida en $<$ https://www.abc.es/espana/comunidad-valenciana/abci-gobierno-no-recurrira-leytransexualidad-tras-llegar-acuerdo-generalitat-201801131157_noticia.html>.

54 En sentido parecido se regula el derecho a la identidad de género al margen de la patologización, así como el derecho a identificarse, incluso los menores de edad, conforme a una documentación administrativa expedida al efecto y al margen de la identificación de la persona en el Registro Civil, dentro de la Legislación Valenciana (vid. art.8 y título III de la Ley), en la Legislación Navarra de 2017 (el art.44 hace referencia a la expedición de documentación administrativa propia y el art.4.2 se refiere específicamente a la protección de los menores de edad trans). Igualmente, la Legislación de Aragón de 2018 (vid. arts.6 y 7 específicamente). 
4. Se limitarán las exploraciones genitales a lo estrictamente necesario y siempre por criterios de salud.

5. Se formará al personal sanitario haciendo especial hincapié en la corrección de trato y la privacidad.

6. Se preservará la intimidad del paciente en su historia clínica de manera que no todo el personal sanitario que acceda a ella pueda conocer su cambio de identidad de género, salvo cuando sea estrictamente necesario ${ }^{55}$ 》.

\section{REFLEXIONES FINALES}

Uno de los retos que se plantea en los momentos actuales en el ámbito de las relaciones paterno-filiales como consecuencia del reconocimiento generalizado de la autonomía progresiva del menor para tomar sus propias decisiones se encuentra en el debate sobre la posibilidad de actuación y toma de decisiones de los menores, en las denominadas edades limítrofes.

Precisamente por ello nos hemos centrado en este trabajo en un tema de relevante actualidad como es el de los menores transexuales e intersexuales, donde además del problema de si los mismos pueden equipararse a los adultos para poder solicitar el cambio de sexo y la rectificación registral del mismo, se plantean cuestiones igualmente relevantes, en los casos de intersexualidad, vinculadas con la conveniencia o adecuación de la realización de intervenciones tempranas para que quede determinado de manera definitiva el sexo del menor.

En relación con lo indicado y al hilo de la vigente Ley 3/2007, de 15 de marzo, reguladora de la Rectificación registral de la mención relativa al sexo de las personas, conforme a la cual se exige la mayoría de edad para solicitar la rectificación en el Registro Civil del sexo de las personas transexuales se ha analizado la más reciente doctrina y jurisprudencia, así como las diferentes propuestas legislativas destinadas a permitir el cambio de sexo durante la minoría de edad y al hilo de la ya numerosa normativa autonómica reguladora de los derechos de las personas LGTBI y específicamente de los menores de edad. Igualmente se ha analizado la posición mantenida por el TS en su Auto de 10 de marzo de 2016 en el que se plantea Cuestión de inconstitucionalidad contra la citada Ley 3/2007, por excluir a los menores de edad del ámbito de aplicación de la misma.

Significativo y preocupante resulta, como en otros muchos ámbitos del derecho, la delantera asumida, como se ha indicado, por parte de las Comunidades Autónomas (CCAA) al abordar en los últimos años, cosa que no ha hecho el legislador nacional, dentro de las denominadas leyes de identidad de género o en defensa de los derechos de las personas

Vid. en sentido parecido el art.17 de la Ley Foral Navarra de 29.6.2017; el art. 29 de la Ley Andaluza de 28.12.2017; el art. 23 de la Ley Catalana de 10.10.2010; el art. 23 de la Ley de Baleares de 30.5.2016; el art. 11 de la Ley de 8.4.2015 de Extremadura; los arts. 4.4. y 15 de la Ley de 19.4.2018 de Aragón o el art. 16 de la Ley de 27.5.2016 de Murcia. 
LGTBI, su aplicación y reconocimiento en relación con los menores de edad, creando una situación compleja y de difícil encaje con la normativa estatal al permitir en algunos casos la incorporación del sexo o género «sentido» por parte de los menores en registros administrativos, académicos o sanitarios, al margen de los datos incorporados al Registro Civil como sistema de identificación único y común de todos los españoles.

Por ello resulta imprescindible, en los momentos actuales, una toma de decisión por parte del Poder legislativo del Estado, que aúne y unifique criterios dando una cobertura uniforme a un tema de la relevancia del que se aborda en el presente trabajo, resultando de todo punto inadmisible una diferenciación de criterios (administrativos/registrales) en relación a un aspecto de la persona tan relevante como es su propia identidad, máxime cuando, atendiendo a un principio esencial de nuestro ordenamiento como es la protección del "interés superior del menor" es precisamente a los menores a los que afecta.

\section{BIBLIOGRAFÍA}

ÁLVAREZ RODRÍGUEZ, I., «La organización de las Naciones Unidas y el derecho a la no discriminación por motivo de orientación sexual e identidad de género: apuntes para un debate», RGDC, núm. 17, 2013 (Monográfico El movimiento LGTB en perspectiva constitucional, ELVIRA PERALES, A., MATÍA PORTILLO, J., ARROYO GIL, A., coords.), pp. 1-34.

ALVENTOSA DEL RIO, J., «Menores transexuales. Su protección jurídica en la Constitución y en la legislación española», REDC, núm. 107, 2016, pp.153-189. Disponible en $<$ http://dx.doi.org/10.18042/cepc/redc.10705>

BENAVENTE MOREDA, P., «Identidad y contexto inmediato de la persona (identidad personal, el nombre de la persona, identidad sexual y su protección)», AFDUAM, núm. 17, 2013, pp.105-144.

BENAVENTE MOREDA P., «Orientación sexual e identidad de género y relaciones jurídico privadas», RGDC, núm. 17, 2013, pp.1-75.

BERCOVITZ RODRÍGUEZ-CANO, R., «Personas transexuales y estado de derecho», Revista Doctrinal Aranzadi Civil-Mercantil, núm. 11/2018, Tribuna (BIB 2018/13976).

BERNINI, L., Las teorías Queer. Una introducción (trad. Albert Tola), BarcelonaMadrid (Egales), 2018.

CAMPS MERLO, M. Identidad sexual y Derecho. Estudio interdisciplinario del transexualismo, Pamplona (Eunsa), 2007. 
DÍAZ LAFUENTE, J., «La protección de los derechos fundamentales frente a la discriminación por motivos de orientación sexual e identidad de género en el Unión Europea», RGDC, núm. 17, 2013 (Monográfico El movimiento LGTB en perspectiva constitucional, ELVIRA PERALES, A., MATÍA PORTILLO, J., ARROYO GIL, A., coords.), pp. 1-48.

ELVIRA PERALES, A., «Transexualidad y derechos», RGDC, núm. 17, 2013, (Monográfico El movimiento LGTB en perspectiva constitucional, ELVIRA PERALES, A., MATÍA PORTILLO, J., ARROYO GIL, A., coords.), pp. 1-29.

FAUSTO STERLING, A, «The Five Sexes», Revista Sciences, 1993, (ed. revisado posteriormente en 2000).

FAUSTO STERLING, A, Cuerpos sexuados: La política de género y la construcción de la sexualidad (2000), (traducido al español), Barcelona (Melusina), 2006.

FENTON-GLYNN, C., «The legal status of intersex persons in Australia», en SCHERPE J.M., DUTTA, A. and HELMS T. (eds.), The legal Status of intersex persons, Cambridge (Intersentia), 2018, pp. 243-253.

FERRER RIBA, J., y LAMARCA MARQUÉS, A., «The legal status of transgender and transexual persons in Spain», en SCHERPE, J.M. (ed.), The legal Status of Transsexual and Transgender persons, Cambridge (Intersentia), 2015, pp.261-279.

GIOSA, LM., SCHIRO, M.V., DUNNE, P., «The legal status of transexual and transgender persons in Argentina» en SCHERPE, J.M. (ed.) The legal status of transsexual and trangender persons, Cambridge (Intersentia), 2015, pp.571-584.

HELMS, T., «The 2013 German law: Analysis and criticism» en SCHERPE J.M., DUTTA, A. and HELMS T. (eds.), The legal Status of intersex persons, Cambridge (Intersentia), 2018, pp. 369-381.

HUGHES, I,. «Biology of fetal sex development», en SCHERPE J.M., DUTTA, A. and HELMS T. (eds.), The legal Status of intersex persons, Cambridge (Intersentia), 2018, pp. 25-44.

JOY GREEN, F., FRIEDMAN, M., (eds.), Buscando el final del Arcoiris: una exploración de las prácticas de crianza desde la fluidez de género, [Traducido por Yolanda Fontal y revisado por Raquel (Lucas) Platero], Barcelona (Bellaterra), 2015.

LAUROBA LACASA, E., «Las personas intersexuales y el derecho: Posibles respuestas jurídicas para un colectivo invisible», Derecho Privado y Constitución, núm. 32, 2018, pp. 11-54.

LÓPEZ GUZMAN, J., Transexualismo y salud integral de la persona. Valencia (Tirant lo Blanch), 2016. 
LOPEZ MORATALLA, $\mathrm{N}$, «La identidad sexual: personas transexuales y con trastornos del desarrollo gonadal "no existen sexos, solo roles": un experimento antropológico necesitado de la biotecnología», Cuadernos de Bioética, núm. 78, vol. XXIII, (2012). Disponible en: <http://www.aebioetica.org/revistas/2012/23/78/341.pdf.>

MALDONADO, J., «El reconocimiento del derecho a la identidad sexual de los menores transexuales en los ámbitos registral, educativo y sanitario», RJUAM, núm. 36, 2017-II, pp.135-169

DE MONTALVO JÄÄSKELAINEN, F., «Problemas legales acerca del tratamiento médico de la disforia de género en menores de edad transexuales», $R G D C$, núm. 24, 2017, pp. 1-31.

NIETO PIÑEROBA, J. A., Transexualidad, Intersexualidad y dualidad de género, Barcelona (Bellaterra), 2008.

PFÄFFLIN, P., «Transgenderism and transsexuality medical and psichological viewpoints», en SCHERPE, J.M. (ed.), The legal status of transexual and transgender persons, Cambrigde (Intersentia), 2015, pp.12-23.

PLATERO MÉNDEZ, R., Transexualidades. Acompañamiento, factores de salud y recursos educativos, 2. ${ }^{\mathrm{a}}$ ed., Barcelona (Bellaterra), 2014.

RAVETLLAT BALLESTÉ, I., «El derecho a la identidad (de género) de la infancia y la adolescencia: del paradigma de la patología a la autodeterminación», $L a$ Leydigital, LA LEY 11968/2017, pp. 1-31

RUIZ-RUISUEÑO MONTOYA, F., «Los derechos de las personas LGTB en la Jurisprudencia del TEDH», RGDC, núm. 17, 2013, (Monográfico El movimiento LGTB en perspectiva constitucional, ELVIRA PERALES, A., MATÍA PORTILLO, J., ARROYO GIL, A. coords.), pp. 1-39.

SANCHEZ FREYRE, JM., «La mayoría de edad como requisito para la rectificación registral del sexo y el nombre: una cuestión de derechos fundamentales», Revista sobre la infancia y la adolescencia, núm. 14, abril 2018, pp. 39-52.

SANZ-CABALLERO, S,. «El Tribunal Europeo de Derechos Humanos y su respuesta al reto de la transexualidad: Historia de un cambio de criterio», American University International law review, (Washington), Tomo 29, núm. 4, pp. 831-868.

WARD, J., «iAparta tu género binario de mi infancia!: hacia un movimiento a favor de la autodeterminación de género en la infancia», en JOY GREEN, F., FRIEDMAN, M. (eds.), Buscando el final del Arcoiris: una exploración de las prácticas de crianza desde la fluidez de género, Traducido por Yolanda Fontal y revisado por Raquel (Lucas) Platero, Barcelona (Bellaterra), 2015, pp. 59-68. 
YRONWODE, A., «Las personas intersexuales cuestionan las operaciones realizadas en la infancia», Archivo y Biblioteca de Lesbianas, Mujeres Bisexuales y Diferentes (Traducción: Alejandra Sardá), publicado en la revista Synapse, Universidad de California, EEUU, abril 1999, consultado en: <www.isna.org/node/64>. 